\begin{tabular}{|c|c|}
\hline Title & $\begin{array}{l}\text { High-resolution seismic velocity structure beneath the Hokkaido corner, northern Japan: A rc-arc collision and origins of } \\
\text { the } 1970 \text { M } 6.7 \text { Hidaka and } 1982 \text { M } 7.1 \text { Urakawa oki earthquakes }\end{array}$ \\
\hline Author(s) & Kita, Saeko; Hasegawa, A kira; Nakajima, Junichi; Okada, Tomomi; Matsuzawa, Toru; Katsumata, Kei \\
\hline Citation & $\begin{array}{l}\text { Journal of Geophysical Research: Solid Earth, 117(B12), B12301 } \\
\text { https://doi.org/10.1029/2012/B009356 }\end{array}$ \\
\hline Issue Date & $2012-12$ \\
\hline Doc URL & http:/hdl.handle.net/2115/52799 \\
\hline Rights & @2012 A merican Geophysical Union \\
\hline Type & article \\
\hline File Information & JGRSE117-B12_B12301.pdf \\
\hline
\end{tabular}

Instructions for use 


\title{
High-resolution seismic velocity structure beneath the Hokkaido corner, northern Japan: Arc-arc collision and origins of the 1970 M 6.7 Hidaka and 1982 M 7.1 Urakawa-oki earthquakes
}

\author{
Saeko Kita, ${ }^{1}$ Akira Hasegawa, ${ }^{1}$ Junichi Nakajima, ${ }^{1}$ Tomomi Okada, ${ }^{1}$ Toru Matsuzawa, ${ }^{1}$ \\ and Kei Katsumata ${ }^{2}$
}

Received 2 April 2012; revised 26 September 2012; accepted 30 September 2012; published 6 December 2012.

[1] Using travel time data from both a nationwide dense seismic network and a dense temporary seismic network, we obtain a high-resolution three-dimensional seismic velocity structure beneath the Hokkaido corner. Considerable inhomogeneity in the seismic velocity structure is clearly imaged above the subducting Pacific slab. Our results indicate that a broad low-velocity zone of $\mathrm{P}$ and $\mathrm{S}$ waves, with velocities consistent for crustal rocks, is observed west of the Hidaka main thrust at depths of 35-90 km. The images also indicate that several smaller-scale high-velocity zones are located at depths of 0-35 km, striking approximately north-south and inclined to the east-northeastward at $40^{\circ}-60^{\circ}$. All of these anomalous high-velocity zones are located at the deeper extension of Neogene thrust faults. The clearest high-velocity zone is located beneath the Hidaka metamorphic belt and is in contact with the eastern edge of the broad low-velocity zone. Moreover, the boundary between the clearest high-velocity and the broad low-velocity zones corresponds to the fault plane of the $1970 \mathrm{Mj}$ (magnitude determined by the Japan Meteorological Agency) 6.7 Hidaka earthquake. The western boundary of another small high-velocity zone, at depths of 20 to $30 \mathrm{~km}$ within the broad low-velocity zone, corresponds to the fault plane of the $1982 \mathrm{Mj} 7.1$ Urakawa-oki earthquake. These observations suggest that these two large and anomalously deep inland earthquakes occurred at sharp material boundaries under a northeast-southwest compressional stress field caused by ongoing arc-arc collision process.

Citation: Kita, S., A. Hasegawa, J. Nakajima, T. Okada, T. Matsuzawa, and K. Katsumata (2012), High-resolution seismic velocity structure beneath the Hokkaido corner, northern Japan: Arc-arc collision and origins of the 1970 M 6.7 Hidaka and 1982 M 7.1 Urakawa-oki earthquakes, J. Geophys. Res., 117, B12301, doi:10.1029/2012JB009356.

\section{Introduction}

[2] The Hidaka collision zone (HCZ) is an arc-arc type collision zone located at the center of the island of Hokkaido, Japan, which has been the subject of many previous studies [e.g., Komatsu and Nochi, 1966; Kimura, 1994, 1996]. The Kuril forearc is juxtaposed against the northeastern (NE) Japan arc in central Hokkaido along the Hidaka main thrust (Figure 1), striking approximately north-south. Based on geological investigations, Kimura [1994] reported that the Kuril forearc has been colliding with the NE Japan arc since the middle Miocene due to the southwestward migration of

\footnotetext{
${ }^{1} \mathrm{RCPEV}$, Graduate School of Science, Tohoku University, Sendai, Japan.

${ }^{2}$ Institute of Seismology and Volcanology, Hokkaido University, Sapporo, Japan.

Corresponding author: S. Kita, RCPEV, Graduate School of Science, Tohoku University, 6-6 Aza-Aoba, Aramaki, Aoba-ku, Sendai 980-8578, Japan. (kita@aob.geophys.tohoku.ac.jp)

(C2012. American Geophysical Union. All Rights Reserved. 0148-0227/12/2012JB009356
}

the Kuril forearc sliver, forming an arc-arc type collision zone (HCZ). The southwestward migration of the Kuril forearc has been suggested to be due to the oblique subduction of the Pacific Plate beneath the Kuril forearc [Kimura, 1994, 1996]. Recent GPS geodetic surveys [Geographical Survey Institute, 1998] have also shown that the Kuril arc is migrating southwestward relative to the NE Japan arc. Previous studies have examined the crustal structure of central Hokkaido using seismic reflection and refraction surveys in order to obtain images at shallow depths $(<\sim 40 \mathrm{~km})$ and understand the collision process of the two forearcs [Japan National Oil Corporation, 1973, 1987, 1993, 1996; Ikawa et al., 1997; Arita et al., 1998; Moriya et al., 1998; Iwasaki et al., 1998, 2004; Tsumura et al., 1999; Ito, 2000].

[3] Beneath the Hidaka collision zone, M7 class inland earthquakes have occurred approximately every 40 years, including two recent large earthquakes in 1970 and 1982 (the $1970 \mathrm{Mj} 6.7$ Hidaka earthquake [Ichikawa, 1971; Moriya, 1972] and the $1982 \mathrm{Mj} 7.1$ Urakawa-oki earthquake [Moriya et al., 1983]; Figure 1). The focal depths of these two large inland earthquakes and aftershocks $(20$ to $30 \mathrm{~km}$ 


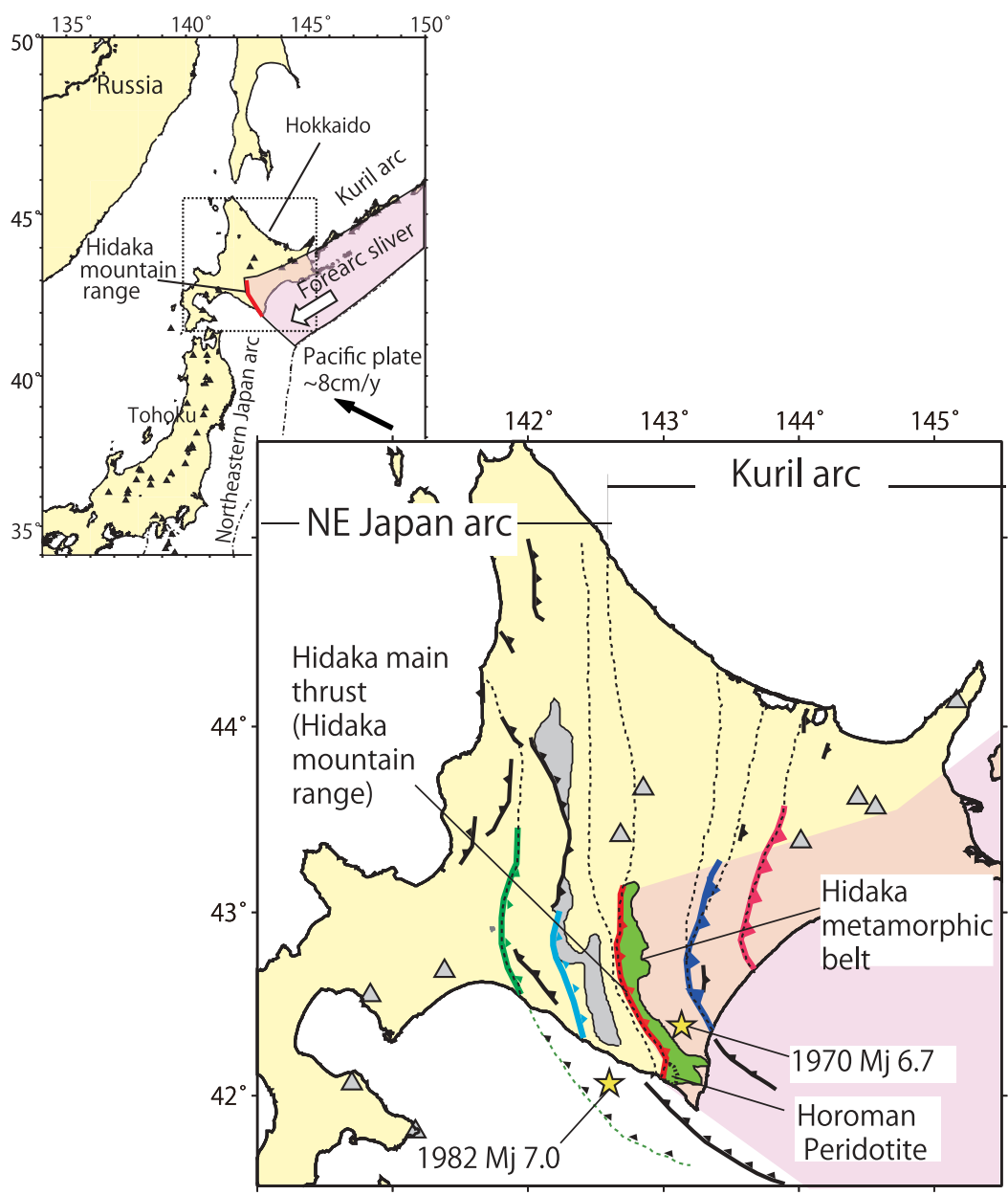

Figure 1

Figure 1. Tectonic setting of Hokkaido (modified after Iwasaki et al. [2004], originally from Kimura [1994] and Geological Survey of Japan [1992]). Main plot is an enlarged image of the squared area in the inserted map. The pink zone shows the Kuril forearc. Dotted lines indicate tectonic boundaries. Thick lines with triangles denote Quaternary and Neogene thrust faults (orange: Ishikari Lowland eastern edge fault system; yellow: Yubari-dake fault [Ito, 2000]; red: Hidaka main thrust; blue: Tokachi Plain faults: purple: Urahoro fault; black: other thrust faults). Green and gray shaded areas show the Hidaka metamorphic belt and the Kamuikotan metamorphic belt, respectively. Stars indicate the hypocenters of the 1970 Hidaka and the 1982 Urakawa-oki earthquakes. Thick blue lines mark geological boundaries. Triangles are sites of active volcanoes.

for the 1970 earthquake and its aftershocks [Moriya, 1972]; 18 to $35 \mathrm{~km}$ for the 1982 earthquake and its aftershocks [Moriya et al., 1983]) are anomalously deep compared with those of most inland earthquakes in the Japanese islands $(\sim 15 \mathrm{~km})$, but the detailed reason for this remains unclear.

[4] Numerous previous studies have also investigated the three-dimensional (3D) $\mathrm{P}$ and $\mathrm{S}$ wave velocity structures, seismicity, and characteristics of focal mechanisms of events in central Hokkaido [Takanami, 1982; Fuji and Moriya, 1983; Miyamachi and Moriya, 1984; Miyamachi et al., 1994; Kosuga et al., 1996; Murai et al., 2003; Katsumata et al., 2003, 2006; Ogiso et al., 2005; Kita et al., 2006, 2010a, 2010b]. Recently, a very dense seismic network (Kiban observation network) has covered all of the Japanese islands at station intervals of approximately $20 \mathrm{~km}$, integrating data from Hi-net operated by NIED and other existing seismic networks operated by universities, by the Japan Meteorological Agency (JMA) and by municipal governments. Kita et al. [2010a] carried out a tomographic inversion study above the subducting Pacific slab surface at depths of 0 to $200 \mathrm{~km}$ beneath the Hokkaido corner using the double-difference tomography method [Zhang and Thurber, 2003, 2006] and only using data from the Kiban network with a spatial resolution of approximately $20 \mathrm{~km}$ at depths of 0 to $150 \mathrm{~km}$. The authors concluded that an anomalous low-velocity zone, with seismic velocities of crust materials, is in contact with the upper interface of the subducting Pacific Plate in the Hokkaido corner.

[5] In the present study, we focus on the Hidaka region above the subducting Pacific slab. We investigate the threedimensional seismic velocity structure beneath the Hokkaido 

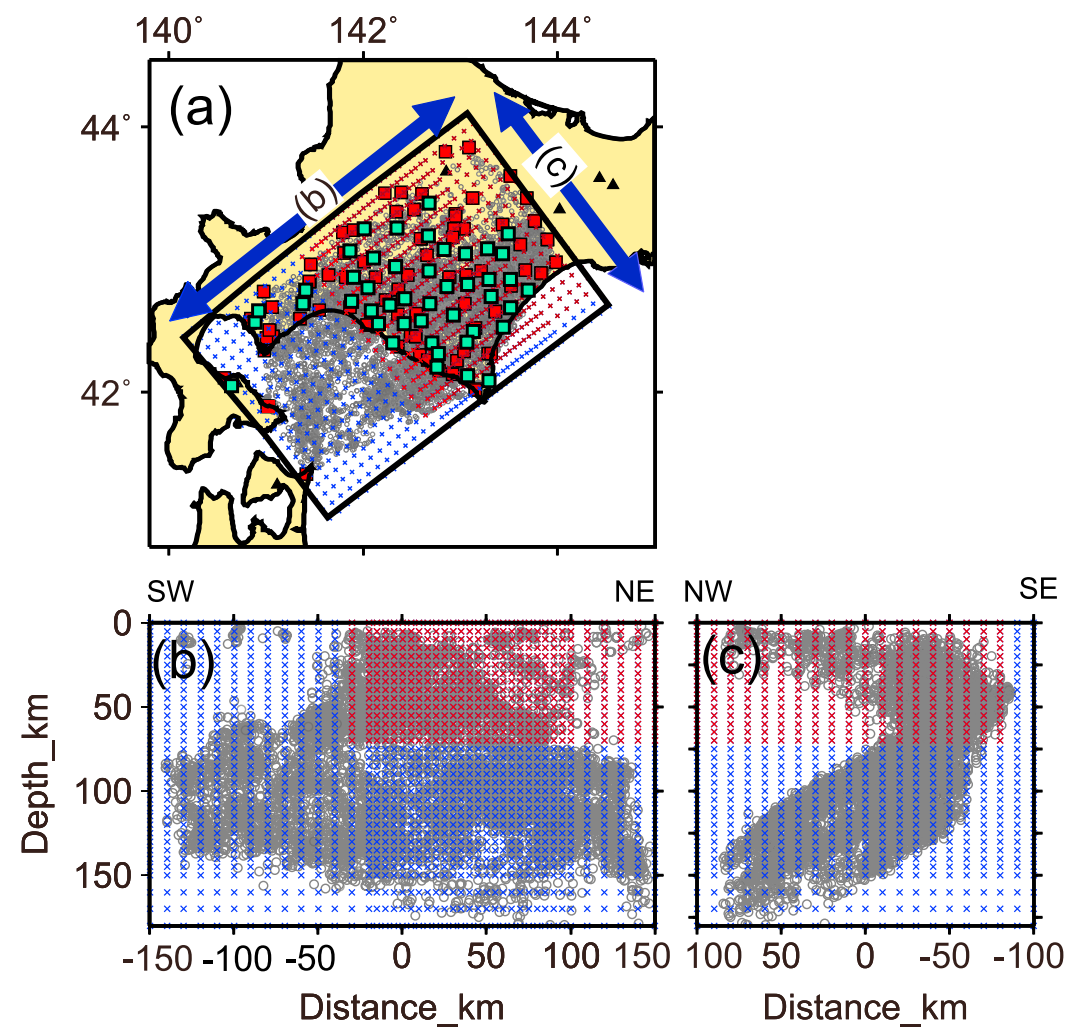

Figure 2. Distribution of earthquakes (gray circles), permanent seismic stations (red squares), temporary seismic stations (green squares [Katsumata et al., 2003]), and grid configurations (red and blue crosses) used in tomoFDD imaging: (a) map view, (b) along-arc, and (c) across-arc vertical cross sections. Black triangles are sites of active volcanoes.

corner using a denser grid setting than that employed by Kita et al. [2010a], in order to examine in detail the structure of the Hidaka region, the collision zone of the NE Japan arc, and the Kuril forearc sliver in the Hokkaido corner. In our tomographic inversion, we also include a data set obtained by a temporary dense seismic network covering the area around the Hidaka mountain range [Katsumata et al., 2002] in addition to the data set previously used in Kita et al. [2010a], which further improves the spatial resolution for the Hidaka mountain range region. We then compare the obtained velocity images with the fault planes of the two large inland earthquakes (in 1970 and 1982) in the Hidaka region and discuss the collision processes in the Hokkaido corner.

\section{Geology of the Hidaka Region, Central Hokkaido}

[6] The geology of the Hidaka collision zone has several notable features related to the arc-arc collision process. Central Hokkaido consists of N-S trending zonal geological units [Geological Survey of Japan, 1992; Kimura, 1994] (Figure 1). The Hidaka main thrust corresponds to one of the geological unit boundaries, and is the boundary between the Kuril and the NE Japan forearcs. The Hidaka metamorphic belt is located on the east side of the Hidaka main thrust, and comprises high-T type metamorphic rocks of Tertiary age. The main rock types of this metamorphic belt are crustal rocks, which change westward from upper- to lower-crust materials [e.g., Shimura et al., 2004; Komatsu et al., 1983].

[7] On the southwestern edge of the Hidaka metamorphic belt, a large body $\left(8 \times 10 \times 3 \mathrm{~km}^{3}\right)$ of mantle rock is exposed adjacent to lower-crust material (Horoman peridotite) [e.g., Komatsu and Nochi, 1966; Takazawa et al., 1999; Niida, 1984; Ozawa, 2004]. The Horoman peridotite is generally thought to be a diapiric mantle fragment resulting from the arc-arc collision process. Sawaguchi [2004] suggested that the peridotite originated from the uppermost mantle, based on observations of deformation microstructures and olivine lattice preferred orientations.

[8] In section 5, we compare these geological features to our seismic velocity structures in order to reveal further details of the arc-arc collision process.

\section{Three-Dimensional Seismic Velocity Structure Beneath the Hokkaido Corner}

\subsection{Data and Methods}

[9] The double-difference tomography method (TomoFDD) [Zhang and Thurber, 2003, 2006] was applied to 292,840 travel time picks for $\mathrm{P}$ waves and to 219,728 travel time picks for S waves that were recorded at 125 stations for 20,262 earthquakes that occurred in the study area beneath the Hokkaido corner during the period from August 1999 to December 2010 (Figure 2). These travel time picks were compiled from the picks 
obtained manually from the original seismograms in this study (April 2003 to December 2010), from the JMA catalog (June 2002 to December 2010), and from the picks reported by Katsumata et al. [2002] (August 1999 to April 2001). During the period from April 2003 to December 2010, picks obtained manually from original seismograms in our present study were preferentially used. We selected events in the study area with $>10$ travel time picks, an azimuthal gap (i.e., greatest azimuth angle without observation) of less than $180^{\circ}$ and a $\min \Delta$ (epicentral distance to the nearest station) less than the focal depth. The magnitude range of events is $5.7>\mathrm{Mj}>0$. For obtaining differential travel-time data, we made 40,576 pairs of earthquakes. The distances between two earthquakes forming one pair is $<10 \mathrm{~km}$, and the average distance between a pair of hypocenters was $2.7 \mathrm{~km}$. Epicentral distances between a station and a pair of events are $<400 \mathrm{~km}$. Grid intervals were set at 5 to $10 \mathrm{~km}$ in the along-arc direction, $10 \mathrm{~km}$ in the across-arc direction, and 5 to $10 \mathrm{~km}$ in the vertical direction (Figure 2). The initial velocity model adopted in our tomographic study was derived by the following procedure. A 3D velocity model was adopted by linearly interpolating the results of Kita et al. [2010a], apart from the northeastern edge of the study area because the grid intervals in this study are smaller than those in Kita et al. [2010a], and the grid directions are not the same as those in the previous study. An average $1 \mathrm{D}$ velocity structure calculated from Kita et al. [2010a] was adopted for grids on the northeastern edge of the study area, where the velocity structure was not imaged in their study. Initial hypocenters adopted in the tomographic study were those relocated using the 3D velocity structure mentioned above. In the tomographic inversion of our study, velocity values of red grids in Figure 2 at depths of 0 to $75 \mathrm{~km}$ in the Hidaka region were not fixed, and velocity values of blue grids in Figure 2 (outside the area of the Hidaka region and/or at depths of $>80 \mathrm{~km}$ ) were fixed to those of the initial model. This is because the number of raypaths was increased beneath the area around the Hidaka mountain range by utilizing the data set from the dense temporary seismic network of Katsumata et al. [2002]. Damping parameters in the tomographic inversion were chosen by evaluating a trade-off curve of velocity model variance and data variance based on 10 different tests of damping parameters. The final results of the tomographic inversion were obtained after 10 iterations, which reduced the root mean square residuals (misfit between observed and calculated travel times) from 0.27 to $0.14 \mathrm{~s}$ for $\mathrm{P}$ waves and from 0.49 to $0.21 \mathrm{~s}$ for $\mathrm{S}$ waves.

\subsection{Resolution Tests}

[10] We carried out several checkerboard resolution tests (CRTs) to assess the reliability of the obtained results. In one of the CRTs, positive and negative velocity perturbations of $5 \%$ (the anomaly size is $10 \mathrm{~km}$ [along arc] $\times 10 \mathrm{~km}$ [across arc] $\times 10 \mathrm{~km}$ [depth direction]) were assigned alternately to two grid nodes (or one grid node) for the horizontal direction and to two grid nodes for the vertical direction, and the travel times for this model were calculated in order to generate synthetic data. Synthetic data were constructed from the same source-receiver geometry as observations with random noises corresponding to picking errors (standard deviations of $0.10 \mathrm{~s}$ for $\mathrm{P}$ waves and $0.20 \mathrm{~s}$ for $\mathrm{S}$ waves). We then applied the TomoFDD to the synthetic travel times with random noise using a 1D structure model, which was generated by averaging the 3D velocity structure of Kita et al. [2010a]. If the checkerboard pattern was well recovered, we consider the data to be sufficient to resolve velocity anomalies comparable to the lateral extent of the assigned checkerboard patterns. The CRT results indicate that the checkerboard patterns of $\mathrm{P}$ waves are well recovered (those of S waves are a little smeared) in areas at depths from 15 to $60 \mathrm{~km}$ (Figures $3 \mathrm{a}-3 \mathrm{i}$ ) beneath the land area between the Ishikari Lowland eastern edge fault system and the Tokachi Plain faults (i.e., area excluding the upper right portions of vertical slices), which approximately corresponds to areas within contours with a DWS (derivative weighted sum [Thurber and Eberhart-Phillips, 1999]) of 500. DWS is related with the number of raypaths of $\mathrm{P}$ waves (or $\mathrm{S}$ waves) at each velocity grid, but not with the uneven directions of incident (or emergence) angles of raypaths at each velocity grid. We also performed a CRT with velocity perturbations of $10 \%$, and these results are generally similar to those of the CRT with perturbations of $5 \%$. We performed two additional CRTs with perturbations of $5 \%$ and the anomaly size of $15 \mathrm{~km}$ [along arc] $\times 20 \mathrm{~km}$ [across arc] $\times 15 \mathrm{~km}$ [depth direction], and that of $20 \mathrm{~km} \times 20 \mathrm{~km} \times 20 \mathrm{~km}$. The results

Figure 3. (a-e) Results of checkerboard resolution tests (vertical cross-sectional views of along-arc) with anomaly size of $10 \mathrm{~km}$ [along arc] $\times 10 \mathrm{~km}$ [across arc] $\times 10 \mathrm{~km}$ [depth direction] for (left) $\mathrm{P}$ wave and (right) $\mathrm{S}$ waves along lines $\mathrm{A}$ (Figure 3a), B (Figure 3b), C (Figure 3c), D (Figure 3d), and E (Figure 3e) shown in the inset map at the bottom. Contours for which DWS $=500$ are indicated by thin broken black lines. Thick black lines delineate the upper surface of the subducting Pacific slab as estimated in this study. At the top of each panel, bold horizontal lines indicate the land area, and upside-down triangles indicate the locations of thrust faults (orange: Ishikari Lowland eastern edge fault system; yellow: Yubari-dake fault [Ito et al., 1999]; red: Hidaka main thrust; blue: Tokachi Plain faults: purple: Urahoro fault; black: other thrust faults). The green and gray rectangles at the top of each plot indicate the location of the Hidaka and Kamuikotan metamorphic belts, respectively. Red and blue crosses delineate grid configurations. ( $\mathrm{f}-\mathrm{i}$ ) Results of checkerboard resolution tests (horizontal cross-sectional views) with anomaly size of $10 \mathrm{~km}$ [along arc] $\times 10 \mathrm{~km}$ [across arc] $\times 10 \mathrm{~km}$ [depth direction] for (left) $\mathrm{P}$ wave and (right) $\mathrm{S}$ wave at depths of $15 \mathrm{~km}$ (Figure 3f), $25 \mathrm{~km}$ (Figure $3 \mathrm{~g}$ ), $35 \mathrm{~km}$ (Figure $3 \mathrm{~h}$ ), and $45 \mathrm{~km}$ (Figure $3 \mathrm{i}$ ) for area shown in the inset map at the top right. (j-m) Results of checkerboard resolution tests (horizontal cross-sectional views) with anomaly size of $15 \mathrm{~km} \times 20 \mathrm{~km} \times 15 \mathrm{~km}$ for (left) P wave and (right) $\mathrm{S}$ wave at depths of $15 \mathrm{~km}$ (Figure 3j), $15 \mathrm{~km}$ (Figure 3k), $35 \mathrm{~km}$ (Figure 31), and $45 \mathrm{~km}$ (Figure 3m) shown in the inset map for the area at the top right. $(\mathrm{n}-\mathrm{q})$ Results of checkerboard resolution tests (horizontal cross-sectional views) with anomaly size of $20 \mathrm{~km} \times 20 \mathrm{~km} \times$ $20 \mathrm{~km}$ for (left) $\mathrm{P}$ wave and (right) $\mathrm{S}$ wave at depths of $15 \mathrm{~km}$ (Figure 3n), $25 \mathrm{~km}$ (Figure 3o), 35 km (Figure 3p), and $45 \mathrm{~km}$ (Figure 3q) shown in the inset map at the bottom. Contours with DWS $=500$ are indicated by broken black lines. Gray lines show the locations of thrust faults. The black area and the thick black lines indicate the location of the Hidaka metamorphic belt and the coast line, respectively. 
of the two additional tests at the same depth as Figures $3 \mathrm{f}-3 \mathrm{i}$ are shown in Figures 3j-3q. The checkerboard patterns of $15 \mathrm{~km} \times 20 \mathrm{~km} \times 15 \mathrm{~km}$ of $\mathrm{P}$ waves and $\mathrm{S}$ waves are well recovered (those at depth of $45 \mathrm{~km}$ are a little smeared in east of the Tokachi Plain faults) beneath the land within a DWS of 500 at depths of 5 to $60 \mathrm{~km}$ (Figures 3j-3m; see Figures A2 and A4). The patterns of the CRT of $20 \mathrm{~km} \times 20 \mathrm{~km} \times$ $20 \mathrm{~km}$ are well recovered beneath land within a DWS of 500 (Figures 3n-3q; see Figures A3 and A5).

[11] In order to assess the reliability and robustness of the obtained results and, in particular, the existence of a body of low $\mathrm{P}$ and $\mathrm{S}$ wave velocities and a body of high $\mathrm{P}$ and $\mathrm{S}$ wave velocities directly above the slab, we carried out two types of synthetic tests. These were a reconstruction test (Figure 4) and a restoring resolution test (Figure 5). Figure 4 shows the results of a reconstruction test (RT) where a body with $10 \%$ lower velocities, a body with $12 \%$ higher velocities, a small body with $23 \%$ higher velocities, and a body with 3\% higher velocities are assigned above the slab as a synthetic model that resembles the seismic velocity structure obtained in this paper. Synthetic arrival time data were constructed in a manner similar to the CRT. The synthetic data were then inverted using the 1D structure model used in the CRT. The results of the RT demonstrate that the lowand the high-velocity zones above the slab are well resolved if these zones indeed exist.

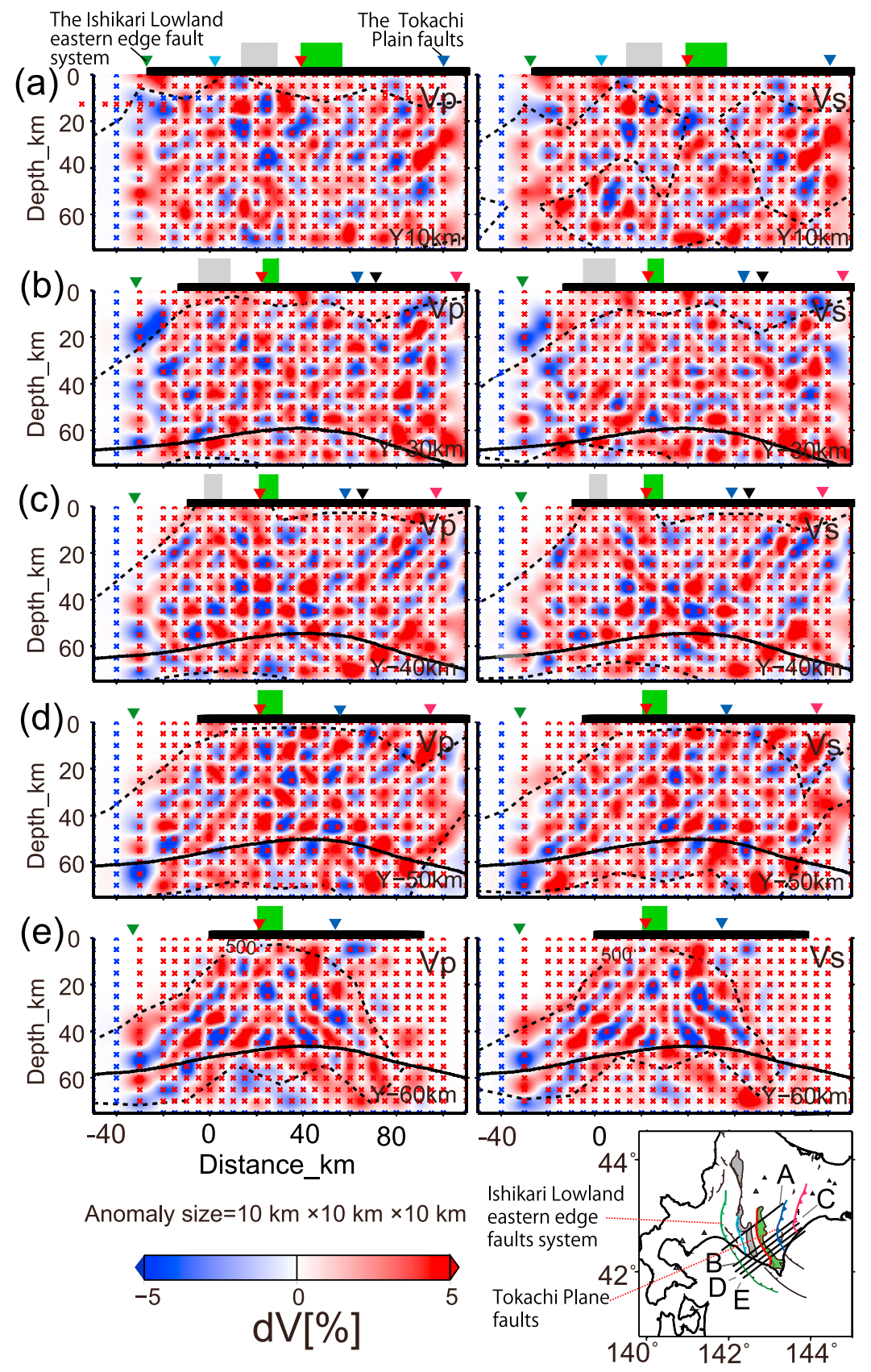

Figure 3 

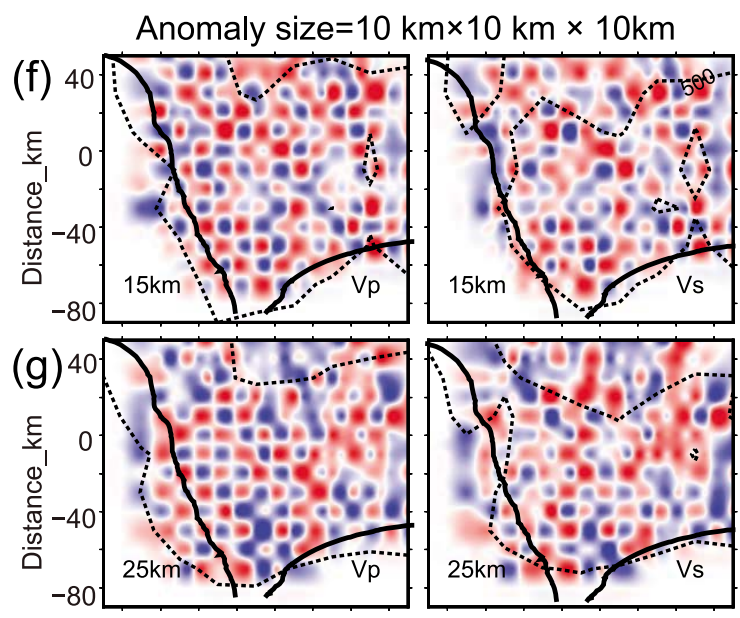

(h)
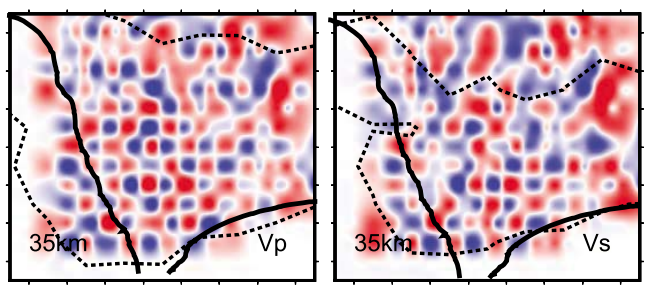

(i)
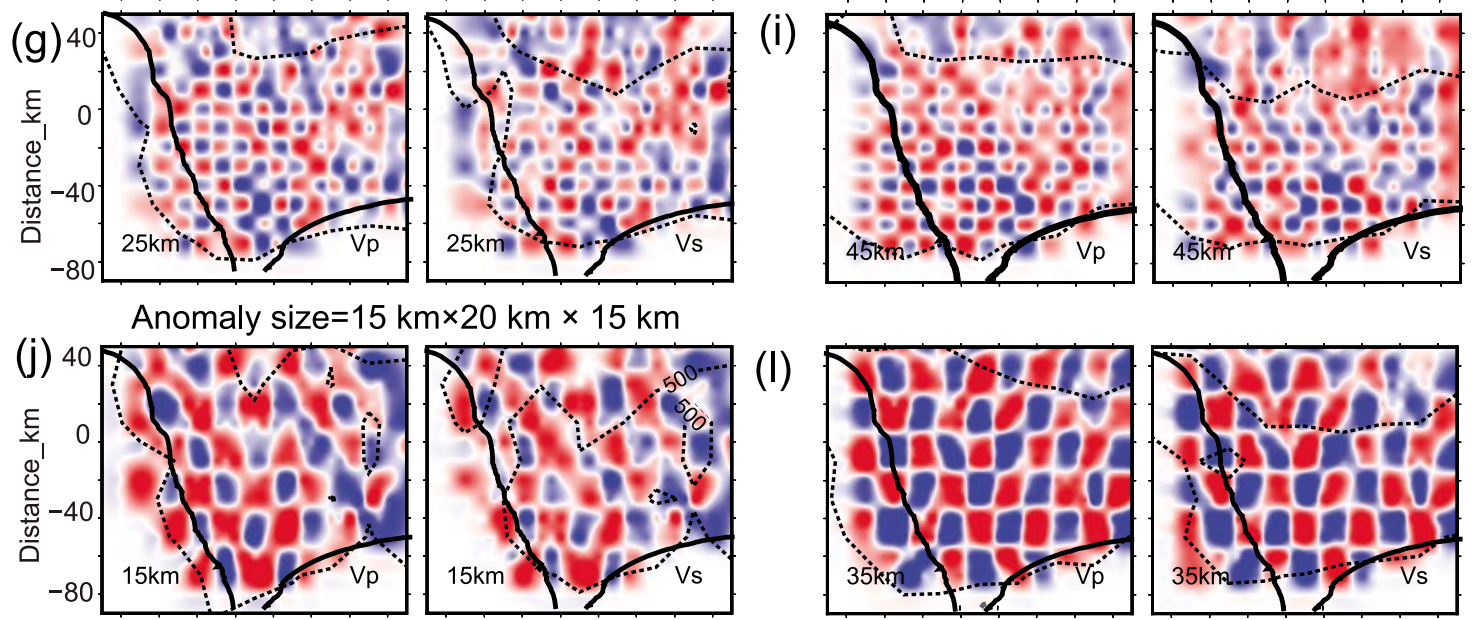

(I)
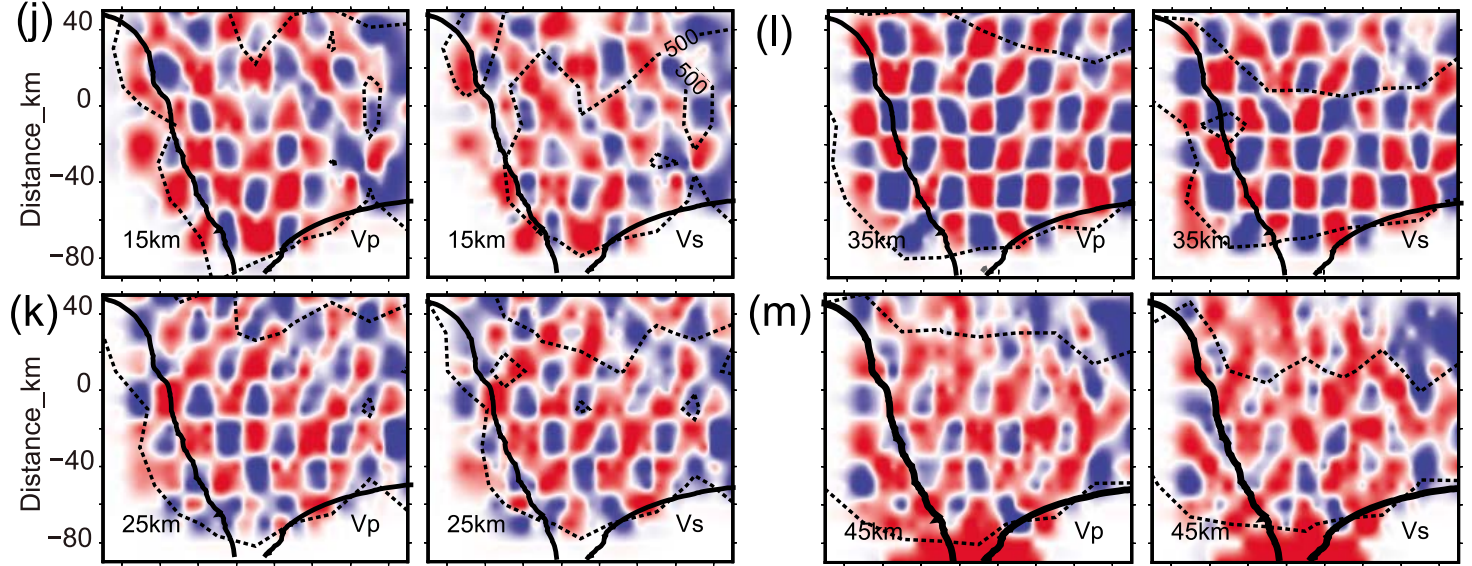

(m)
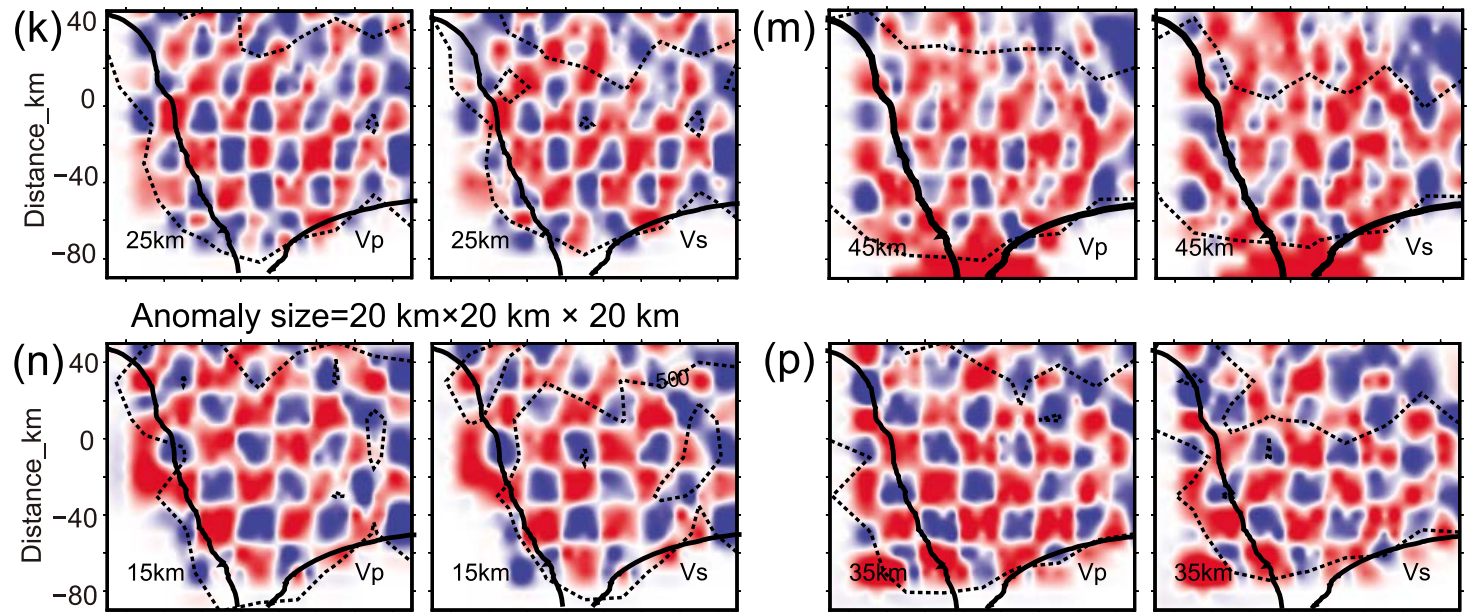

(p)
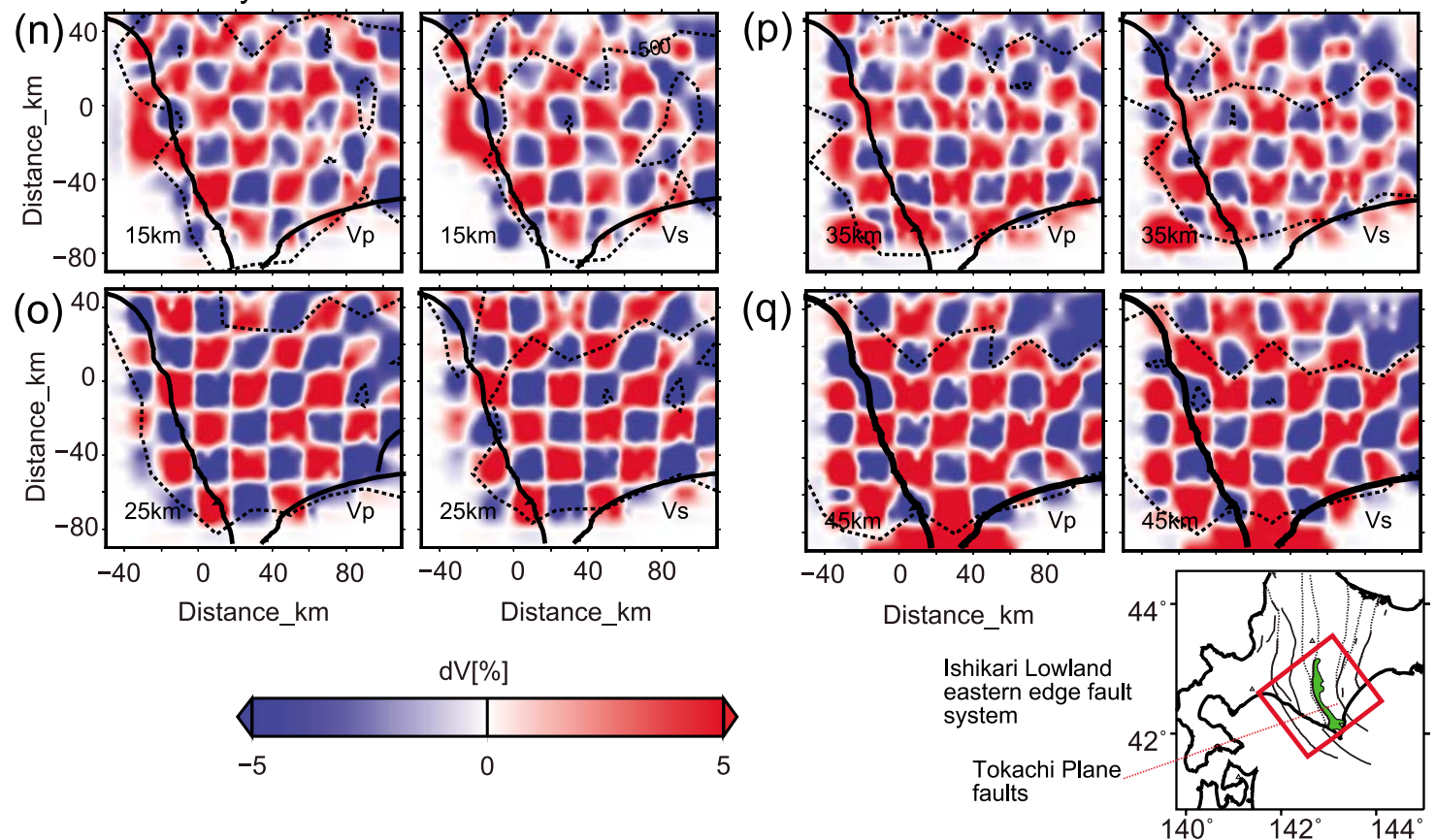

Figure 3. (continued) 
[12] Figure 5 shows the results of a restoring resolution test (RRT) [Zhao et al., 1992]. In the RRT, the obtained 3D structures were adopted as an input (i.e., synthetic) model, and the synthetic arrival times for the model were calculated. The synthetic travel time data were then inverted using the 1D structure model used in the CRT and the RT. The results obtained by the RRT are similar to the results of the tomographic inversions (Figures 6-8), which indicates that the obtained images are reliable. At depths of 5-10 km, at which the original checkerboard pattern are not well recovered, results of RT and RRT are recovered (Figures 4 and 5). Then,
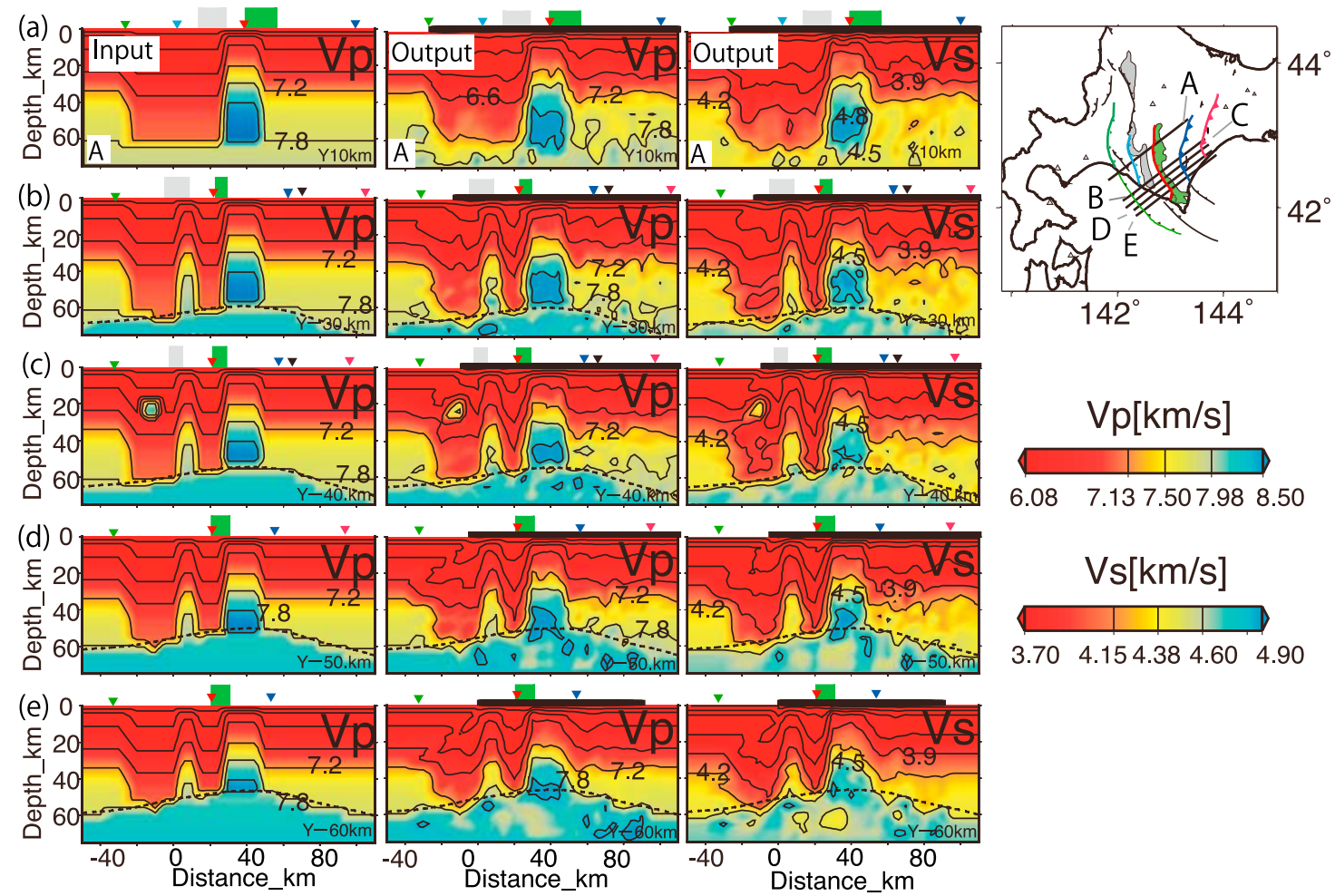

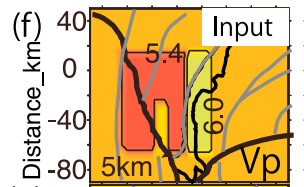

(g)
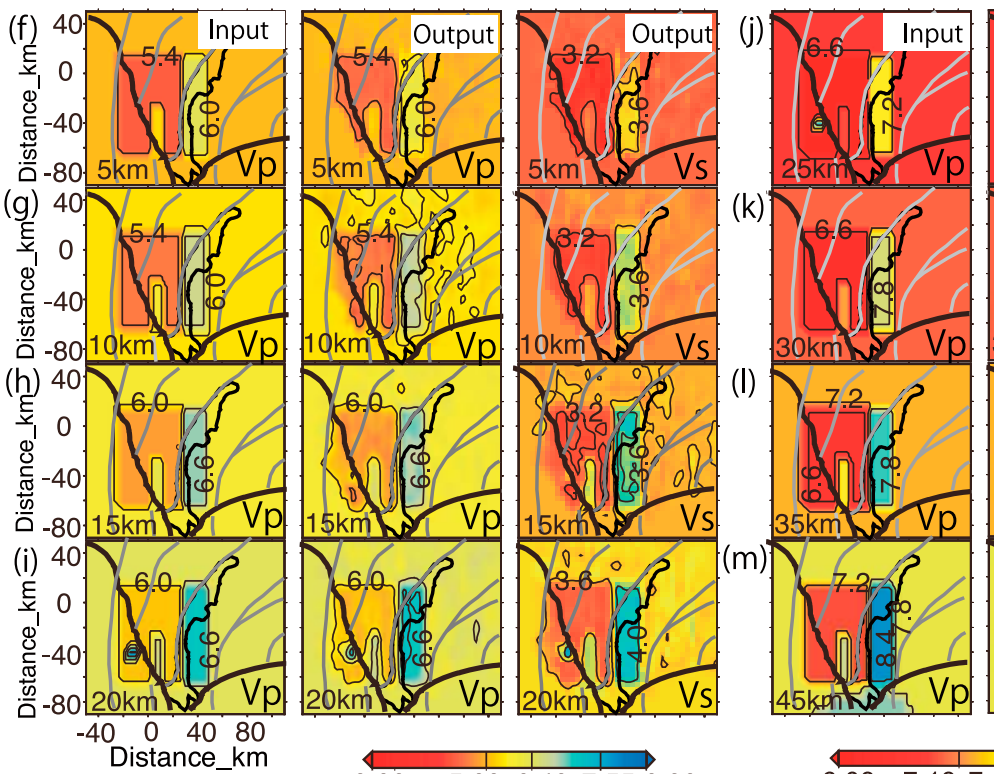

$(\mathrm{k})$

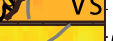

(I)
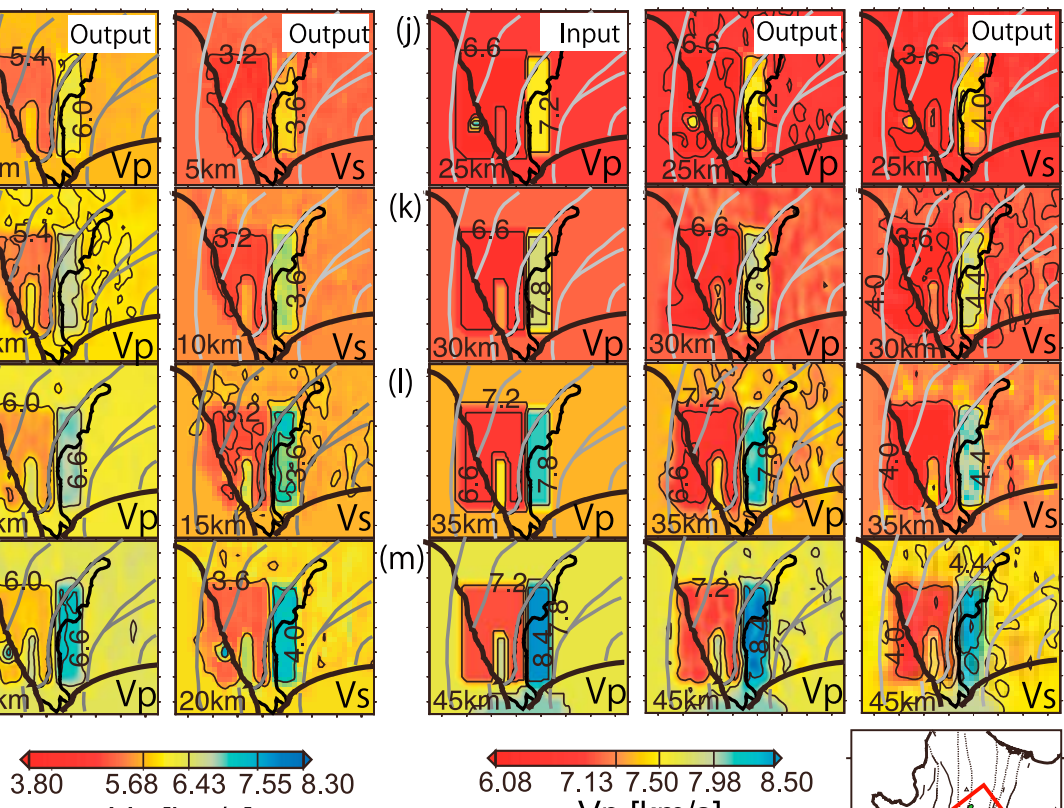
$\mathrm{Vp}[\mathrm{km} / \mathrm{s}]$

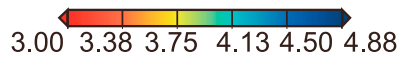

Vs $[\mathrm{km} / \mathrm{s}]$

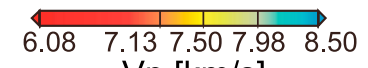
$\mathrm{Vp}[\mathrm{km} / \mathrm{s}]$

$3.70 \quad 4.15 \quad 4.38 \quad 4.604 .90$ $\mathrm{Vs}[\mathrm{km} / \mathrm{s}]$

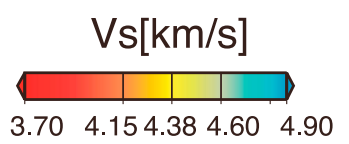

Figure 4 

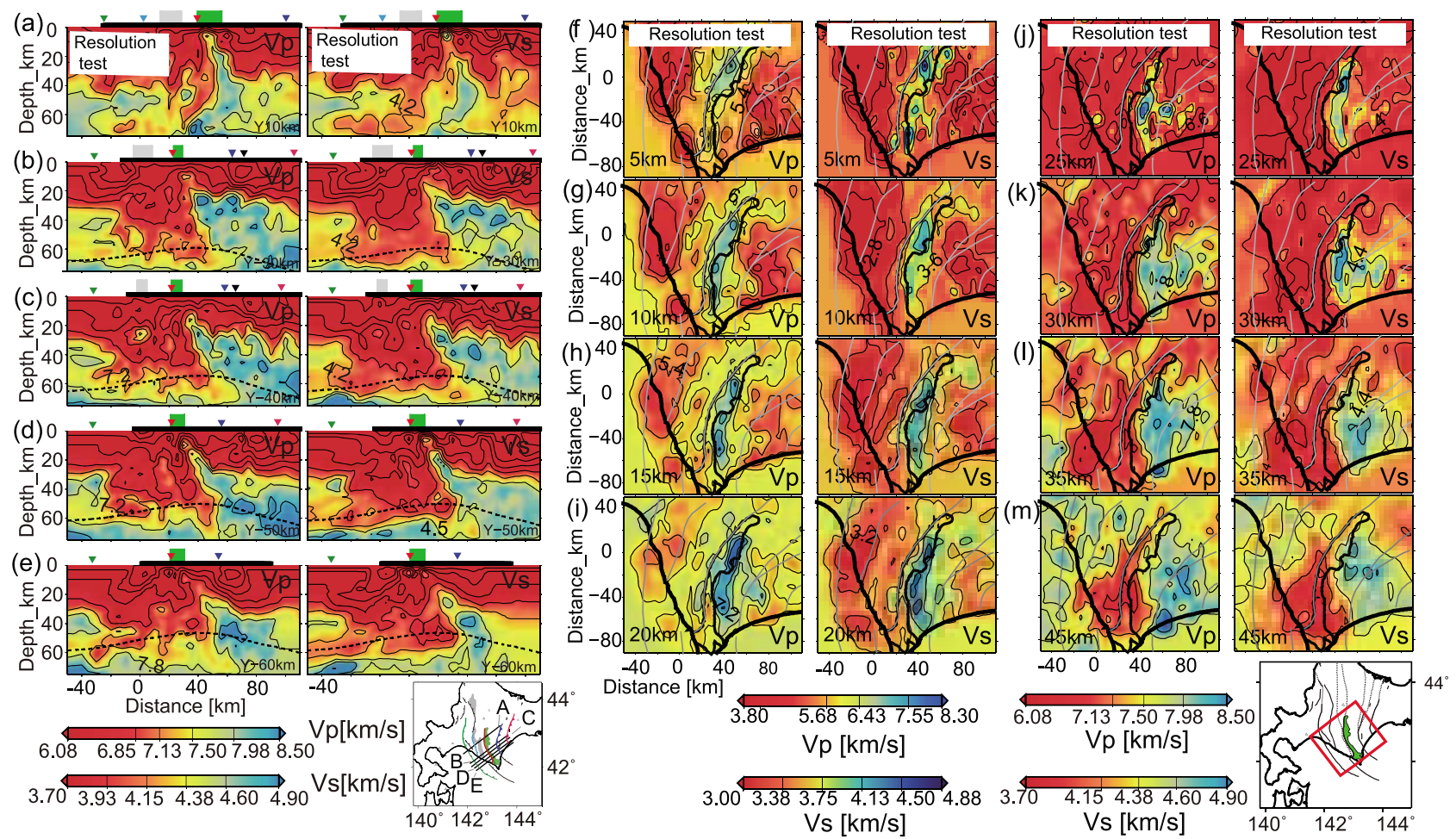

Figure 5. (a-e) Results of the restoring resolution test (vertical cross-sectional views of along-arc) for (left) $\mathrm{P}$ waves and (right) $\mathrm{S}$ waves (vertical cross-sectional views) along lines A (Figure 5a), B (Figure 5b), $\mathrm{C}$ (Figure 5c), D (Figure 5d) and E (Figure 5e) E shown in the inset map at the bottom left. The other symbols are the same as in Figures 4a-4e. (f-i) Results of the restoring resolution test for (left) $\mathrm{P}$ waves and (right) S waves (horizontal cross-sectional views at depths of 5 to $20 \mathrm{~km}$ ). Other symbols are the same as in Figures $4 \mathrm{f}-4 \mathrm{i}$. $(\mathrm{j}-\mathrm{m})$ Results of the restoring resolution test for (left) $\mathrm{P}$ waves and (right) $\mathrm{S}$ waves (horizontal cross-sectional views at depths of 25 to $45 \mathrm{~km}$ ). The symbols are the same as in Figures $4 \mathrm{j}-4 \mathrm{~m}$.

we think that the results of tomographic image at depths of $5-10 \mathrm{~km}$ would be accordingly reliable.

\section{Results: High-Resolution Image of the Broad Low-Velocity and High-Velocity Zones Near the Surface}

[13] Along-arc vertical cross sections of the obtained velocity structure are shown on the left in Figures 6a-6e for $\mathrm{P}$ waves and on the right in Figures 6a-6e for $\mathrm{S}$ waves. Horizontal cross sections are shown in Figures 7 and 8.
Seismic velocity structures were imaged in the Hokkaido corner at depths of 0 to $120 \mathrm{~km}$ and more inhomogeneous structures with high-resolution were obtained than our previous study [Kita et al., 2010a] in the Hidaka region at depths of 0 to $70 \mathrm{~km}$. Figures 6 and 8 show that a lowvelocity anomalous zone of $\mathrm{P}$ and $\mathrm{S}$ waves having $\mathrm{P}$ wave velocities ranging mainly from 6.6 to $7.2 \mathrm{~km} / \mathrm{s}$ and $\mathrm{S}$ wave velocities of $<4.2 \mathrm{~km} / \mathrm{s}$ is distributed in the mantle wedge beneath the Hidaka region to offshore at depths of 35 to $90 \mathrm{~km}$. This spatial distribution of the low-velocity zone is consistent with that of the low-velocity zone reported by

Figure 4. (a-e) (left) Input model and results of the reconstruction test (vertical cross-sectional views of along-arc) of (middle) P wave and (right) S wave velocity structures along lines A (Figure 4a), B (Figure 4b), C (Figure 3c), D (Figure 4d) and $\mathrm{E}$ (Figure 4e) shown in the inset map at the top right. Velocities are shown by the color scale of the right side. Thick broken lines delineate the upper surface of the subducting Pacific slab as estimated in this study. At the top of each plot bold horizontal lines and upside-down triangles show the land area and locations of thrust faults, respectively. The green and gray rectangles at the top of the plots show the locations of the Hidaka and Kamuikotan metamorphic belts, respectively. (f-i) (left) Input model and results of the reconstruction test for (middle) $\mathrm{P}$ and (right) $\mathrm{S}$ waves (horizontal cross-sectional views at depths of 5 to $20 \mathrm{~km}$ ). Cross section locations are shown in the inset at the bottom right. Velocities are shown by the color scale of the bottom left. Note that the color scale is different from that in Figures 4a-4e. Gray lines show the locations of thrust faults. The black area and the thick black lines indicate the locations of the Hidaka metamorphic belt and the coastal line, respectively. ( $\mathrm{j}-\mathrm{m}$ ) (left) Input model and results of the reconstruction test for (middle) $\mathrm{P}$ and (right) $\mathrm{S}$ wave (horizontal cross-sectional views at depths of 25 to $45 \mathrm{~km}$ ). Color scales are the same as in Figures $4 \mathrm{a}-4 \mathrm{e}$. The other symbols are the same as in Figures $4 \mathrm{f}-4 \mathrm{i}$. 

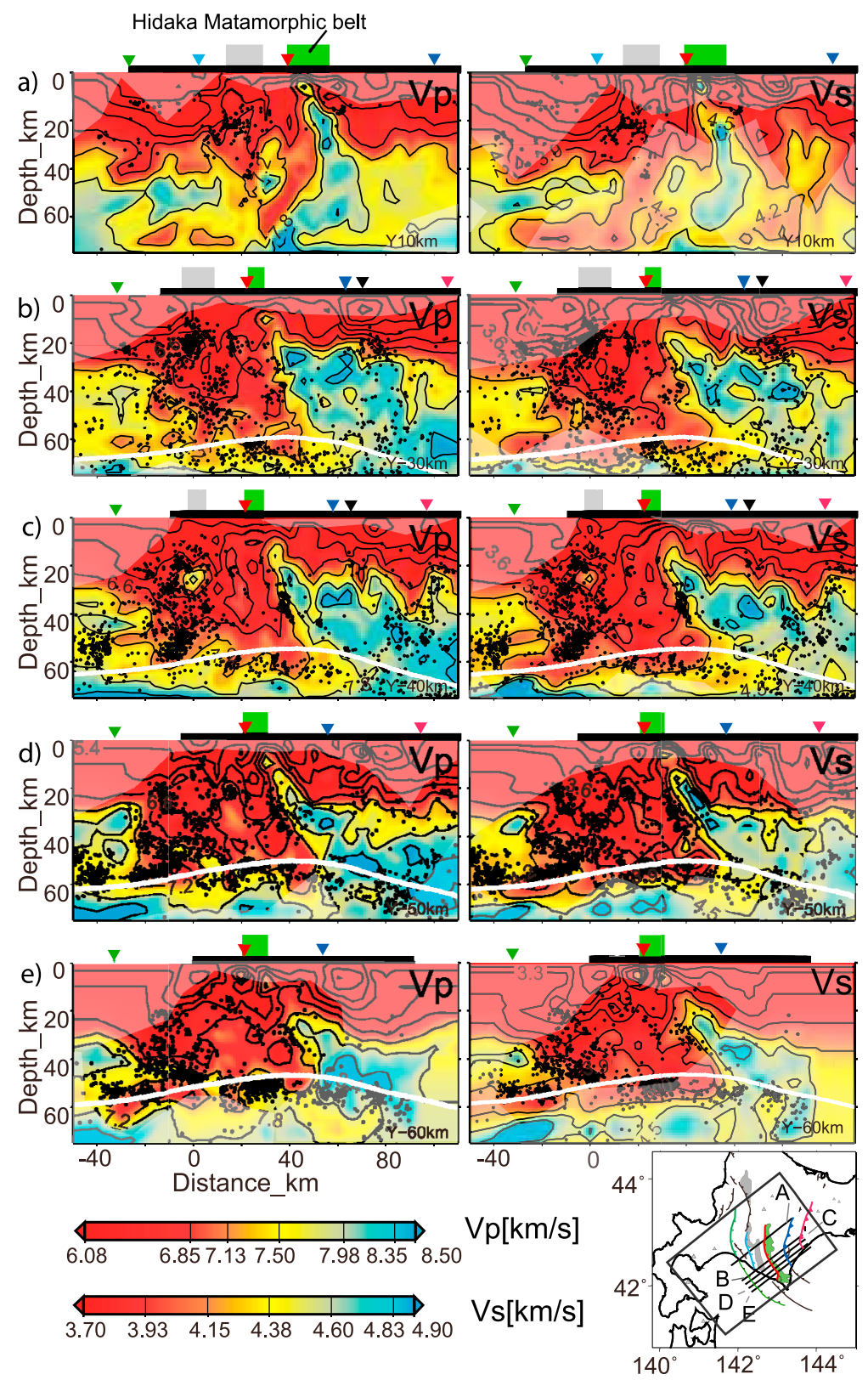

Figure 6. Along-arc vertical cross sections along five lines shown in the inset. (left) $\mathrm{P}$ and (right) $\mathrm{S}$ wave velocities are shown by the color scale. Dots show hypocenters used in the tomographic inversions presented in this study. Thick white lines delineate the upper surface of the subducting Pacific slab. Contours indicate $\mathrm{P}$ and $\mathrm{S}$ wave velocity values contoured at intervals of 0.6 and $0.3 \mathrm{~km} / \mathrm{s}$, respectively. Bold horizontal lines at the top of each plot represent the land area. Squares at the top of the plots indicate the locations of thrust faults (brown: thrust (extension of the Ishikari Lowland eastern edge faults group system); orange: Yubari-dake fault, red: Hidaka main thrust, blue: Tokachi Plain faults; green: Urahoro fault). The green and gray rectangles and the gray area at the top of the plot indicate the locations of the Hidaka and Kamuikotan metamorphic belts, respectively. Gray triangles are sites of active volcanoes. White shaded areas show portions of DWS $<500$.

Kita et al. [2010a] and with the relatively low-velocity zone beneath the Kamuikotan metamorphic belt (east of the Hidaka metamorphic belt), reported by Takanami [1982]. Moreover, these figures show that the low-velocity zone observed in our present study appears to continue from the NE Japan arc, but not from the Kuril forearc because of a continuous high-velocity zone at depths of $15 \mathrm{~km}$ to $35 \mathrm{~km}$ beneath the Hidaka mountain range (the area between the Kuril forearc crust and the NE Japan forearc crust). The highvelocity zone exists more clearly than that of results in Kita et al. [2010a] and several synthetic tests (CRT, RT, and RRT) in this study have shown that the images obtained of the highvelocity zone beneath the Hidaka mountain range are reliable. $\mathrm{Vp} / \mathrm{Vs}$ ratio values in this low-velocity zone range from 1.60 to 

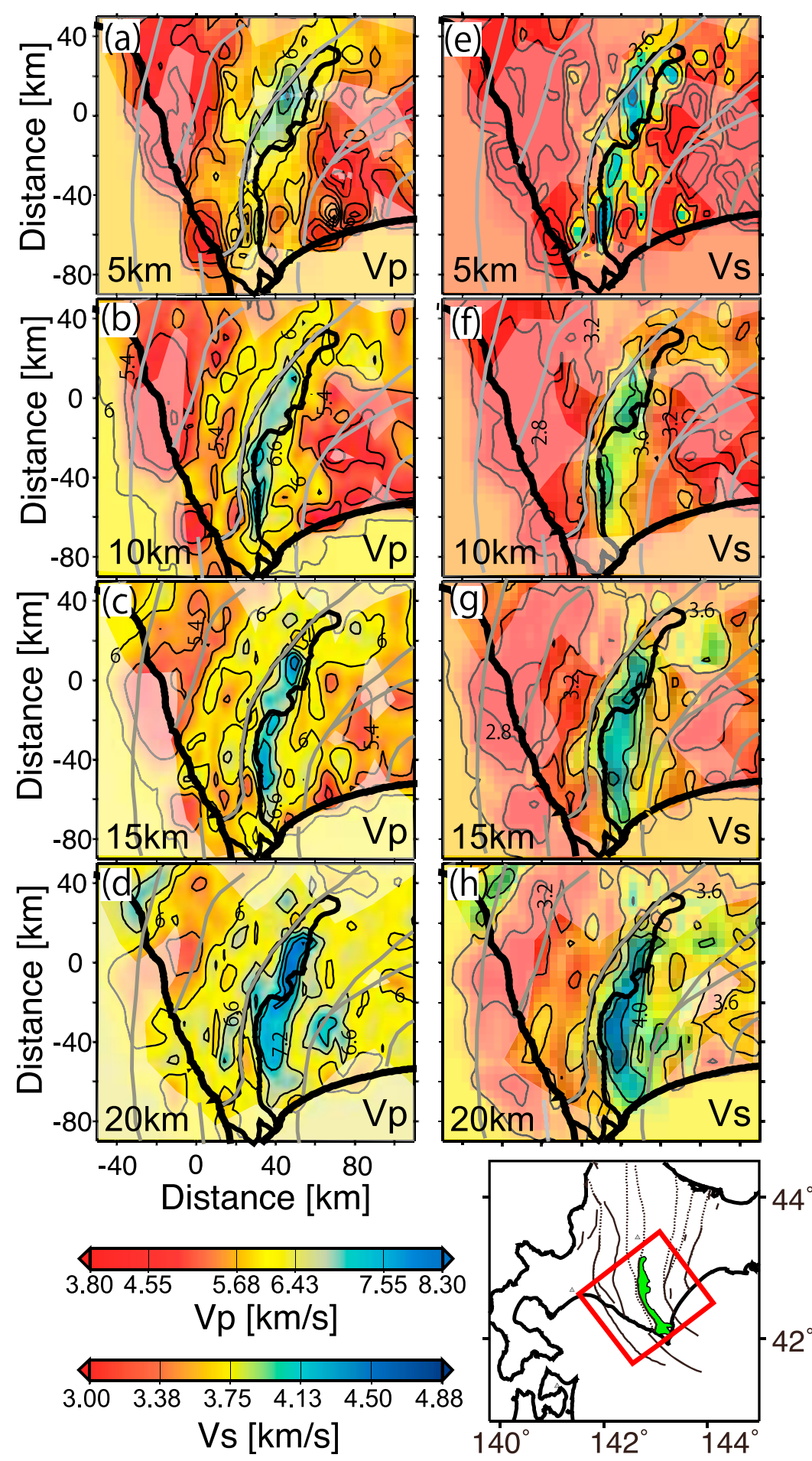

Figure 7. $(\mathrm{a}-\mathrm{h})$ Horizontal cross sections of $\mathrm{P}$ and $\mathrm{S}$ wave velocities. $\mathrm{P}$ wave velocities are shown at depths of 5, 10, 15, and $20 \mathrm{~km}$ in Figures $7 \mathrm{a}-7 \mathrm{~d}$, respectively, and $\mathrm{S}$ wave velocities are shown at these depths are shown in Figures $7 \mathrm{e}-7 \mathrm{~h}$. Note that the color scales are different from those shown in Figures 6. Contours indicate $P$ and $S$ wave velocity values contoured at intervals of 0.6 and $0.4 \mathrm{~km} / \mathrm{s}$, respectively. Gray lines mark the locations of thrust faults. The black area and thick black lines show the locations of the Hidaka metamorphic belt and the coast line, respectively. White shaded areas show portions of DWS $<500$.

1.71, suggesting that the low-velocity zone is not serpentinized mantle wedge material because $\mathrm{Vp} / \mathrm{Vs}$ values for serpentine are generally larger than 2.0 [Christensen, 1996]. The velocity values of the low-velocity zone obtained in our present study are the same as those determined by Kita et al. [2010a], who interpreted this low-velocity zone as crustal material.

[14] The horizontal cross sections (particularly in Figures 7b, $7 \mathrm{c}, 7 \mathrm{~g}, 8 \mathrm{a}, 8 \mathrm{~b}, 8 \mathrm{e}$, and 8f) indicate that the structures of alternate 


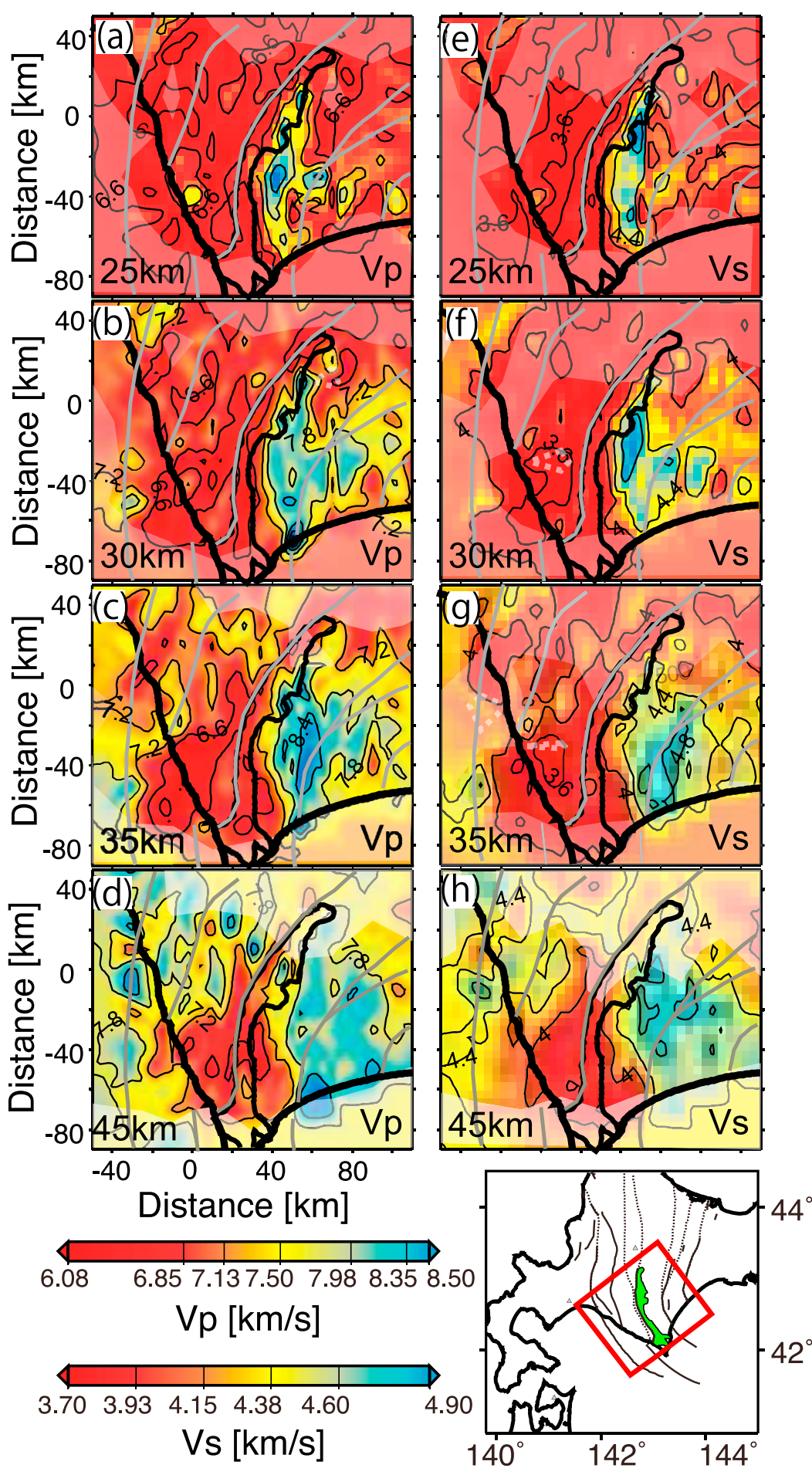

Figure 8. $(\mathrm{a}-\mathrm{h})$ Horizontal cross sections of $\mathrm{P}$ and $\mathrm{S}$ wave velocities. $\mathrm{P}$ wave velocities are shown at depths of 25, 30, 35, and $45 \mathrm{~km}$ in Figures $8 \mathrm{a}-8 \mathrm{~d}$, respectively, and the $\mathrm{S}$ wave velocities are shown at these depths in Figures $8 \mathrm{e}-8 \mathrm{~h}$. The color scales are the same as those in Figure 6. Other symbols are the same as in Figure 7.

layers of relatively high- and low-velocity portions are within the broad low-velocity zone at depths of 5 to $30 \mathrm{~km}$, which strike approximately N-S, parallel to the strike of Neogene thrust faults. While the link between these velocity structures of alternate layers and geological structures are found in our study, this link was not recognized in the previous studies.
[15] Figures 6-8 also reveal the presence of several smaller-scale high-velocity zones ( $\mathrm{P}$ wave velocities of 7.5 to $8.4 \mathrm{~km} / \mathrm{s}$ and $\mathrm{S}$ wave velocities of 4.5 to $4.8 \mathrm{~km} / \mathrm{s}$ ) at depths of 15 to $35 \mathrm{~km}$, inclined to the east-northeast at $40^{\circ}$ to $60^{\circ}$. All of these anomalous high-velocity zones appear to be also located at the deeper extensions of Neogene thrust faults 
(Figure 6). Thus, zonal structures parallel to the strikes of Neogene faults were also observed beneath the Kuril forearc. The largest high-velocity zone is located just to the east of the Hidaka metamorphic belt and is in contact with the eastern edge of the aforementioned low-velocity zone (especially in Figure 8). These pronounced high-velocity zones and structures of alternate layers beneath the Hidaka metamorphic belt, and east of it, were not detected in previous studies. Figure 7 shows horizontal cross sections of our tomographic results obtained at depths of 5 to $20 \mathrm{~km}$. These cross sections indicate that relatively high-velocity zones ( $\mathrm{P}$ wave velocities $>6.6 \mathrm{~km} / \mathrm{s}$ and $\mathrm{S}$ wave velocities $>4.0 \mathrm{~km} / \mathrm{s}$ ) are located just beneath the Hidaka metamorphic belt. This high-velocity zone at depths of 5 to $20 \mathrm{~km}$ almost reaches the surface where the Hidaka metamorphic belt crops out, and the southern edge of this zone is located just beneath the Horoman peridotite. Fuji and Moriya [1983] examined the seismic structure beneath central Hokkaido and reported a relatively high-velocity material $(\mathrm{Vp} \sim 6.1 \mathrm{~km})$ as being the normal upper crustal material beneath the Hidaka mountain range at depths of 0 to $15 \mathrm{~km}$. The general tendency of the location of the high-velocity material reported in their study is broadly consistent with the location of the high-velocity material shown in Figures 6-8.

\section{Discussion}

\subsection{High-Velocity Zones, Mantle Materials, and Zonal Structures}

[16] The velocity values of the aforementioned highvelocity zone ( $P$ wave velocities of 7.8 to $8.5 \mathrm{~km} / \mathrm{s}$ and $\mathrm{S}$ wave velocities of 4.5 to $4.8 \mathrm{~km} / \mathrm{s}$ ) at depths of 15 to $35 \mathrm{~km}$ correspond to those of the uppermost mantle materials (e.g., dunite (one of the Peridotite group rocks) [Christensen, 1996]). Vp/Vs ratio values of the high-velocity zone (1.73 to 1.75 ) also correspond to those reported for dunite by Christensen [1996]. The velocity values of mafic eclogite reported by Christensen [1996] are similar to those of the high-velocity zone obtained in the present study, but the $\mathrm{Vp} /$ Vs values of mafic eclogite (1.78) are slightly larger than as those obtained our study. Moreover, Kanamori and Mizutani [1965] measured P and S wave velocities of rocks by ultrasonic measurements, and the results suggested that peridotitegroup rocks from the Horoman peridotite have $\mathrm{P}$ wave velocities of 7.90 to $8.52 \mathrm{~km} / \mathrm{s}$ and $\mathrm{S}$ wave velocities of 4.22 to $4.80 \mathrm{~km} / \mathrm{s}$ at $1 \mathrm{GPa}$. Thus, their velocity results for the Horoman peridotite are also consistent with the velocities of the high-velocity zone in our study.

[17] Yamamoto et al. [2001a, 2001b, 2002] examined the spatial distribution of gravity anomalies beneath Hokkaido and showed that high Bouguer anomalies are located beneath the Hidaka metamorphic belt, striking approximately $\mathrm{N}-\mathrm{S}$. This might be also consistent with the results of our study, which indicates that materials with high velocities exist beneath the Hidaka metamorphic belt.

[18] In the present study, structures of alternating-velocity layers were found not only within the broad low-velocity zone beneath the area west of the Hidaka metamorphic belt, but also within the Kuril forearc beneath the area east of the belt. The strike of the layers is approximately parallel to that of Neogene thrust fault, indicating that the structures of alternate layers in the Hidaka collision zone are related to the activities of thrust faults.

\subsection{Generation of Anomalously Deep and Large Earthquakes in the Crust Beneath the Hokkaido Corner}

[19] As mentioned in the Introduction, M7 class inland earthquakes have occurred beneath the Hokkaido collision zone approximately every 40 years. In the 1930 s, several M7 class inland earthquakes occurred beneath the Hidaka region [Ichikawa, 1971]. A temporary seismic observation by Moriya [1972] started just after the main shock of the $1970 \mathrm{Mj} 6.7$ Hidaka earthquake. He determined the hypocenters of aftershocks of it using data from the temporary seismic stations. He reported that the aftershocks of this earthquake were located at depths of 20 to $30 \mathrm{~km}$ (Figures 9a and 9b). The $1982 \mathrm{Mj} 7.1$ Urakawa-oki earthquake occurred beneath the Hidaka coastal area. Moriya et al. [1983] determined the hypocenters of the 1982 Urakawa-oki earthquake and its aftershocks using data from both permanent and temporary seismic stations, and showed that the main shock and aftershocks were located at depths of 18 to $35 \mathrm{~km}$ (Figures 10a and 10b). The depths of these two large inland earthquakes and their aftershocks are anomalously deep compared with the normal depth limit (approximately $15 \mathrm{~km}$ ) for inland earthquakes in the Japanese islands [Omuralieva et al., 2012]. In order to investigate the reasons for the anomalous depths of these large inland earthquakes and understand their relationship to collision processes, we compare the fault planes of these earthquakes with the detailed seismic structures obtained in our study. The fault planes used in this comparison are constrained as follows.

[20] In the case of the 1982 Urakawa-oki earthquake, we adopted one nodal plane of the focal mechanism as the fault plane of this earthquake, based on the distribution of aftershocks and the focal mechanism of the main shock by Moriya et al. [1983] (Figures 10a, 10b, and 11a). The nodal plane we adopted is shown in Figures 11a, 11c, and 11d. It corresponds to the trend and dip of the cluster of seismicity, including the main shock (Figure 10b). The possible range of the dip of the nodal plane of the focal mechanisms in the vertical section is from $38^{\circ}$ to $44^{\circ}$ (Figures $11 \mathrm{a}$ and $11 \mathrm{c}$ ), which we estimated using polarities of stations from Figure 9 in Moriya et al. [1983]. The error on the location of the main shock estimated by Moriya et al. [1983] is about $1 \mathrm{~km}$.

[21] In the case of the 1970 Hidaka earthquake, we adopted the fault plane from a focal mechanism determined from $\mathrm{P}$ wave polarities of the JMA catalog in our study because Moriya [1972] did not determine the focal mechanism of the main shock. Figures $11 \mathrm{~b}$ and $11 \mathrm{c}$ show the focal mechanism of the 1970 Hidaka earthquake that we determined in this study. We obtained the final focal mechanism by averaging the candidate focal mechanisms of the 1970 Hidaka earthquake, using the method of Horiuchi et al. [1972]. We assume that the main shock occurred within the cluster of aftershocks determined by Moriya [1970] using temporary seismic stations deployed by him after the main shock (Figure 9). The aftershock alignment was mainly distributed at depths of $15 \mathrm{~km}$ to $35 \mathrm{~km}$ and within $10 \mathrm{~km}$ in the horizontal direction (Figure 9b). The direction of the $\mathrm{P}$ axis is approximately NE-SW, which is similar to that of the 1982 Urakawa-oki earthquake. Based on the distribution of aftershocks reported by Moriya [1972] (Figures 9a and 9b) and on this focal mechanism, the fault plane of the main shock 


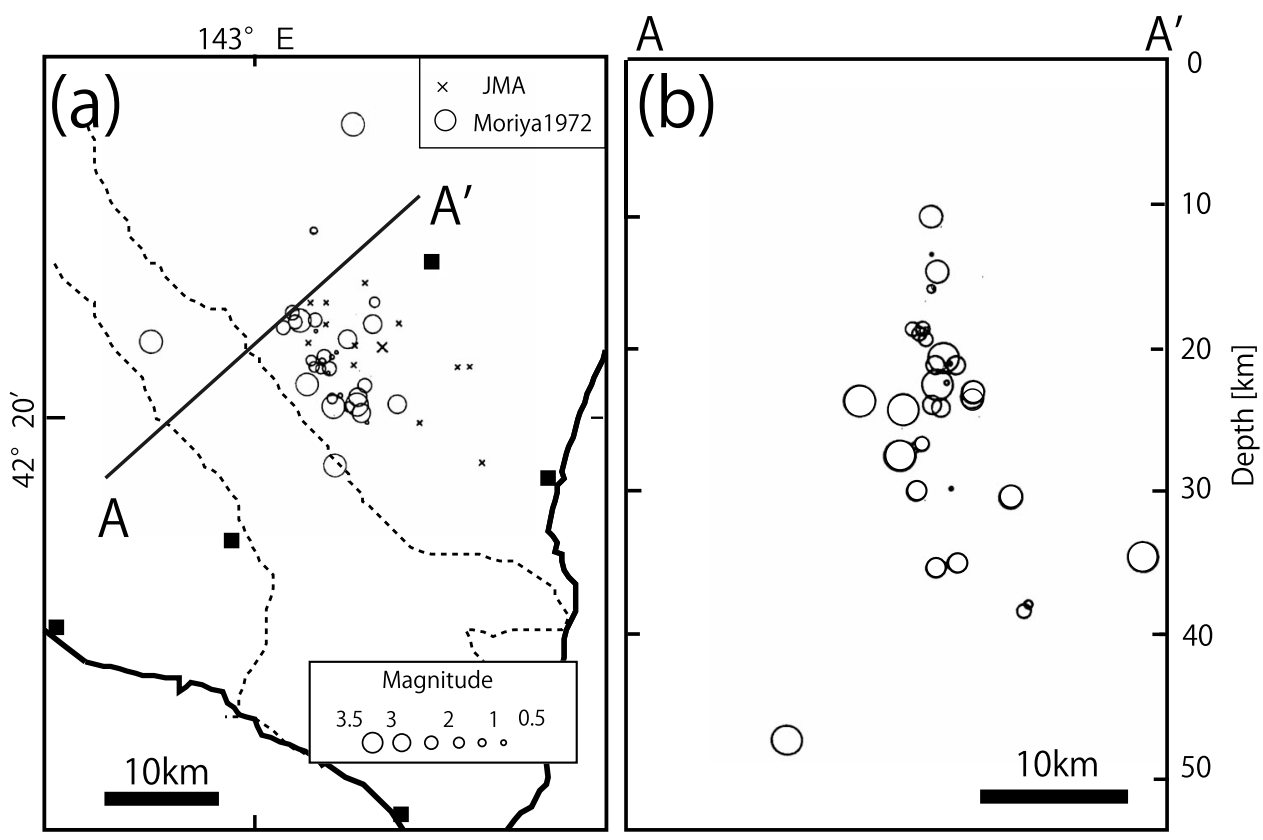

Figure 9. Hypocenter distribution of aftershocks of the $1970 \mathrm{Mj6.7} \mathrm{Hidaka} \mathrm{earthquake} \mathrm{[Moriya,} \mathrm{1972].}$ (a) Map view. Open circles and crosses show aftershocks of the 1970 event determined by Moriya [1972] and by JMA, respectively. The black bold lines and black dashed line show the coast and the location of the Hidaka metamorphic belt, respectively. Black squares show temporary and permanent seismic stations. Circles and crosses show aftershocks of the 1970 event by Moriya [1972] and by JMA, respectively. (b) Along-arc vertical cross section along a line shown in Figure 9a. Circles show aftershocks of the 1970 event by Moriya [1972].

is estimated to strike $333^{\circ}$ and to dip $50^{\circ} \mathrm{E}$ (Figure $11 \mathrm{~b}$ ). The dip of this event and errors on it in the section are $40^{\circ}$ (Figure $11 \mathrm{c}$ ) and about $12^{\circ}$, respectively. In this determination of the focal mechanism, a $1 \mathrm{D}$ velocity structure obtained by Tohoku University [Hasegawa et al., 1978] is used, which is modified by the velocity structure beneath NE Japan. We also attempted to determine a focal mechanism of the 1970 earthquake using the $3 \mathrm{D}$ velocity structure obtained in our study. However, this result was almost identical to that obtained using the $1 \mathrm{D}$ velocity structure, indicating that the difference between the 3D and 1D velocity structures does not affect the determination of the focal mechanism. The description about the location errors of aftershocks and the main shock are not shown in Moriya [1972]. However, the aftershocks are surrounded by dense temporary stations, and that the most of the aftershock events have azimuthal gap of less than 180 degree and a $\min \Delta$ less than the focal depth. Moriya [1972] indicated that $\mathrm{S}$ wave arrival times of the aftershocks could be clearly

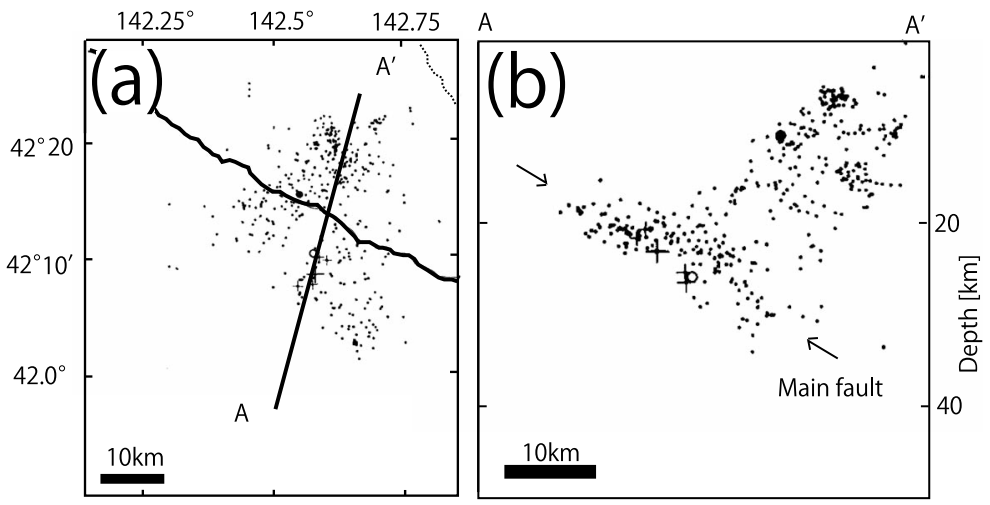

Figure 10. Hypocenter distribution of the $1982 \mathrm{Mj} 7.1$ Urakawa-oki earthquake and its aftershocks [Moriya et al., 1983]. (a) Map view. Large open circle shows the main shock of the 1982 event. Crosses and dots show foreshocks and aftershocks of the 1982 event. The black line and the black dashed line show the coast and the location of the Hidaka metamorphic belt, respectively. (b) Vertical cross section along a line shown in Figure 10a. Arrows show the fault plane of the main shock estimated by Moriya et al. [1983]. Other symbols are the same as in Figure 10a. 
(a)

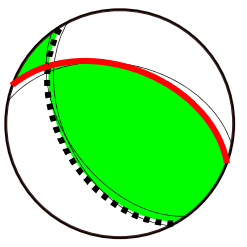

1982 M7.1 (b)

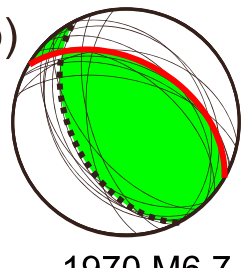

$1970 \mathrm{M} 6.7$
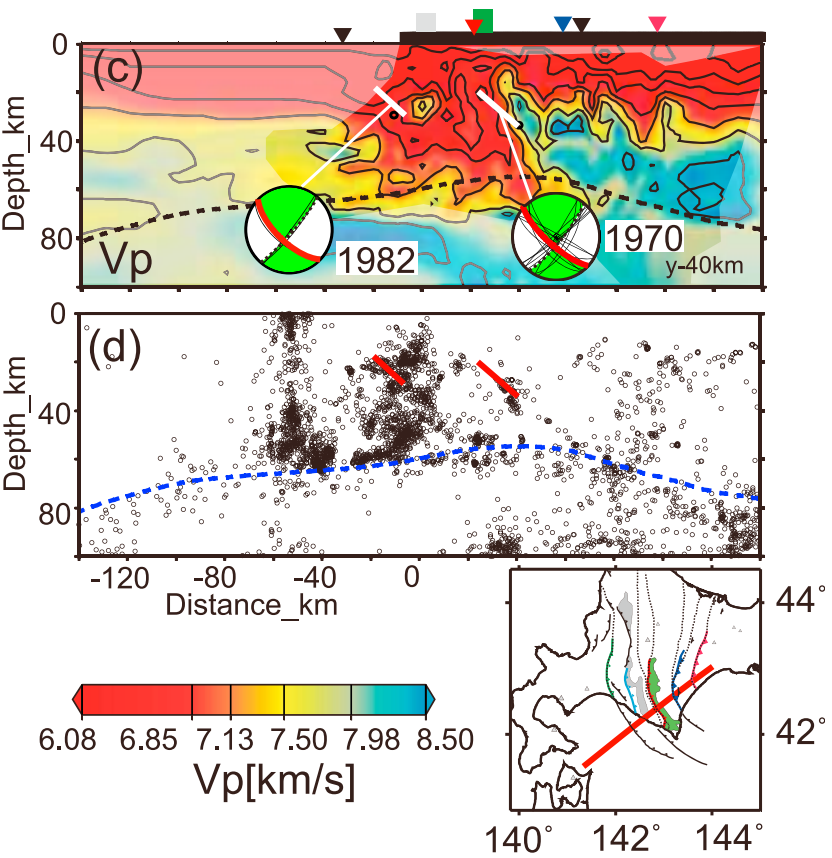

Figure 11. Focal mechanisms of (a) the $1982 \mathrm{Mj} 7.1$ Urakawa-oki earthquake [Moriya et al., 1983] and (b) the $1970 \mathrm{Mj}$ 6.7 Hidaka earthquake (lower hemisphere projection). The solid red line shows a nodal plane. (c) Cross-sectional views of $\mathrm{P}$ wave velocity structure and of (d) earthquakes shown in the inset. The black dashed line Figure 11c and the blue dashed line in Figure 11d delineate the upper surface of the subducting Pacific slab. White lines in Figure 11c and red lines in Figure $11 \mathrm{~d}$ mark the fault planes of the two earthquakes. Beach balls show the focal mechanisms of the 1982 and 1970 events projected on the cross section (lower hemisphere projection).

read and the reading errors for S-P time were within 0.1 (s). Consequently, location errors of events in the main shock fault (aftershocks) in his study would be a couple of kilometers. The main shock was not observed by this temporary seismic network, and only by the distant routine stations. Then, we assumed the main shock hypocenter to be located along the aftershock alignment, and that the possible range of the location of the main shock could be $10 \mathrm{~km}$ in horizontal direction and $20 \mathrm{~km}$ in depth direction.

[22] Figure 11c is a cross-sectional view beneath the Hidaka region, showing the fault plane locations of the two earthquakes. The fault plane of the 1970 M 6.7 earthquake appears to be located at the eastern edge of the broad low-velocity zone (crustal material), and its hanging wall corresponds to the clearest anomalous high-velocity zone (uppermost mantle material) beneath the Hidaka metamorphic belt. The fault plane of the 1970 M 6.7 earthquake is also located at the deeper extension of the Hidaka main thrust. In contrast, the fault plane of the $1982 \mathrm{M} 7.1$ Urakawa-oki earthquake is clearly located at the western boundary of one small-scale high-velocity anomalous zone (uppermost mantle material) within the broad low-velocity zone (crustal material). The fault plane of the Urakawa-oki earthquake also corresponds to the deeper extension of a thrust of the Ishikari Lowland eastern edge fault system. Importantly, both of the fault planes of these large inland earthquakes are located at the boundaries between mantle and crustal materials, the locations of which correspond to the deep extension of thrust faults exposed at the surface. The correspondences between these faults planes and velocity structures, coupled with the reverse fault focal mechanisms, implies that the two inland earthquakes occurred due to the thrust faults acting as low-strength zones, which are facilitated under NE-SW direction compression caused by the collision of the NE Japan and the Kuril forearcs.

\subsection{Spatial Distribution of Seismicity and the Earthquake-Generating Stress Field in the Hokkaido Corner}

[23] We also examined the characteristics of the spatial distribution of deep inland earthquakes and earthquake-

(a)
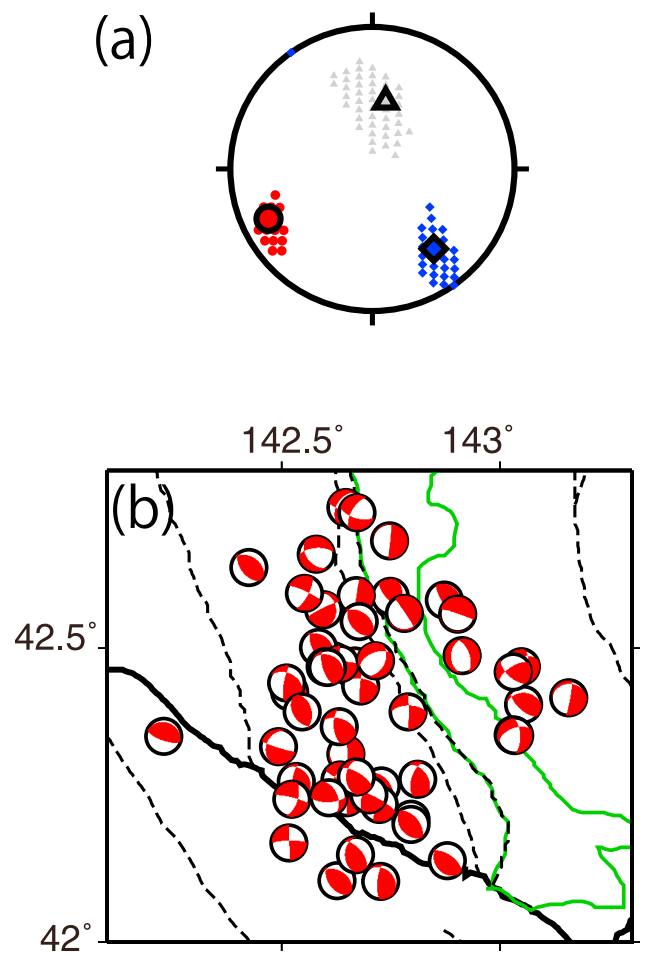

Figure 12. (a) Results of stress tensor inversions in the anomalous low-velocity zone at depths of 0 to $80 \mathrm{~km}$ (crustal material zone) above the Pacific slab. Best fit principal stresses $(\sigma 1, \sigma 2$, and $\sigma 3)$ are plotted as large red circles, large gray triangles, and large blue diamonds, respectively, on the lower focal hemisphere of equal-area projections. Principal stresses falling within the $68 \%$ confidence level are shown as small symbols. (b) Spatial distribution of focal mechanisms in the same region shown in Figure 12a. Black bold line, black dashed lines and green lines delineate the coast, locations of thrust faults and the location of the Hidaka metamorphic belt, respectively. 
Table 1. Stress Tensor Results Beneath the Hokkaido Collision Zone

\begin{tabular}{cccccc}
\hline $\mathrm{N}$ & $\begin{array}{c}\sigma 1 \\
(\text { azimuth/dip) }\end{array}$ & $\begin{array}{c}\sigma 2 \\
(\text { azimuth/dip) }\end{array}$ & $\begin{array}{c}\sigma 3 \\
\text { (azimuth/dip) }\end{array}$ & $\mathrm{R}$ & $\begin{array}{c}\theta \text {-misfit } \\
(\mathrm{deg})\end{array}$ \\
\hline 54 & $224^{\circ} / 20^{\circ}$ & $11^{\circ} / 50^{\circ}$ & $143^{\circ} / 60^{\circ}$ & 0.7 & 19.5 \\
\hline
\end{tabular}

generating stress field within the crust in the Hokkaido corner. Based on $\mathrm{P}$ wave polarity data, we also determined focal mechanisms of smaller events $(\mathrm{Mj} 2.0-4.3)$ that have recently occurred in the identified anomalous crust. We then applied the stress tensor inversion method of Gephart and Forsyth [1984] to these focal mechanisms data, using software developed by Ito et al. [2009]. In determining focal mechanisms, the $\mathrm{P}$ wave polarities used are those read from the original seismograms in this study, the polarities reported by Katsumata et al. [2002], and those in the JMA catalog. The solutions obtained by these inversions for the regions beneath the Hidaka area are shown in Figure 12a. The focal mechanisms used are shown in Figure 12b. Table 1 lists the stress-field parameters, the orientations of the principal stresses $(\sigma 1, \sigma 2$ and $\sigma 3)$, the stress ratio $\mathrm{R}(\sigma 1-\sigma 2 / \sigma 1-\sigma 3)$, and the average misfit $(\theta)$ of the focal mechanism solutions. In Figure 12a, the direction of the maximum principal stress axis is approximately horizontal and strikes NW-SE. The trend of this stress axis is consistent with the $\mathrm{P}$ axis trends of the two large inland earthquakes that have occurred beneath this region, which might indicate that the NW-SE collision process is ongoing.

[24] Figure 11d shows a vertical section through the seismicity (from 1999 to 2010, not including the two large earthquakes) in this area, which were relocated by reapplying the data of this study to the TomoFDD with the 3D seismic velocity structures obtained in this study. The root mean square residuals were reduced from 0.29 to $0.21 \mathrm{~s}$. The mean errors were estimated to be $<3.1 \mathrm{~km}$. For comparison, we also relocated events using the $1 \mathrm{D}$ velocity model proposed by Moriya et al. [1983]. The average distance between hypocenters obtained with the $1 \mathrm{D}$ velocity model and our 3D model is $4.0 \mathrm{~km}$, indicating that we can reliably compare seismicity obtained in our study with previous studies, where hypocenters were relocated using $1 \mathrm{D}$ velocity models. In Figures $11 \mathrm{c}$ and 11d, earthquakes are shown to occur within the anomalous crustal material (i.e., the low-velocity zone) in the mantle wedge at depths of 0 to $75 \mathrm{~km}$ beneath the eastern area of the Hidaka mountain range, including the aftershock areas of the 1982 Urakawa-oki earthquake [Moriya et al., 1983] and the 1970 Hidaka earthquake [Moriya, 1972]. The seismicity around the fault plane of the 1970 Hidaka earthquake (one of the red lines in Figure 11d) is distributed in a linear cluster, dipping approximately $60^{\circ}$. When the seismicity (Figure 11d) is compared with the velocity structure (Figure 11c), it is evident that the seismicity is active in the low-velocity zones of the anomalous crustal materials at depths of 0 to $80 \mathrm{~km}$ beneath the collision zone, but is not active in several high-velocity zones of mantle material.
[25] In general, the depth to the bottom of the seismogenic layer is primarily controlled by temperature. Heat flow in the Hokkaido corner is locally very low compared with surrounding areas [Tanaka, 2004]. The observation of lower temperatures in the Hokkaido corner is also supported by a deepened upperplane seismic belt in the subducting Pacific slab [Kita et al., 2010a]. Kita et al. [2010a] proposed that lower temperature in
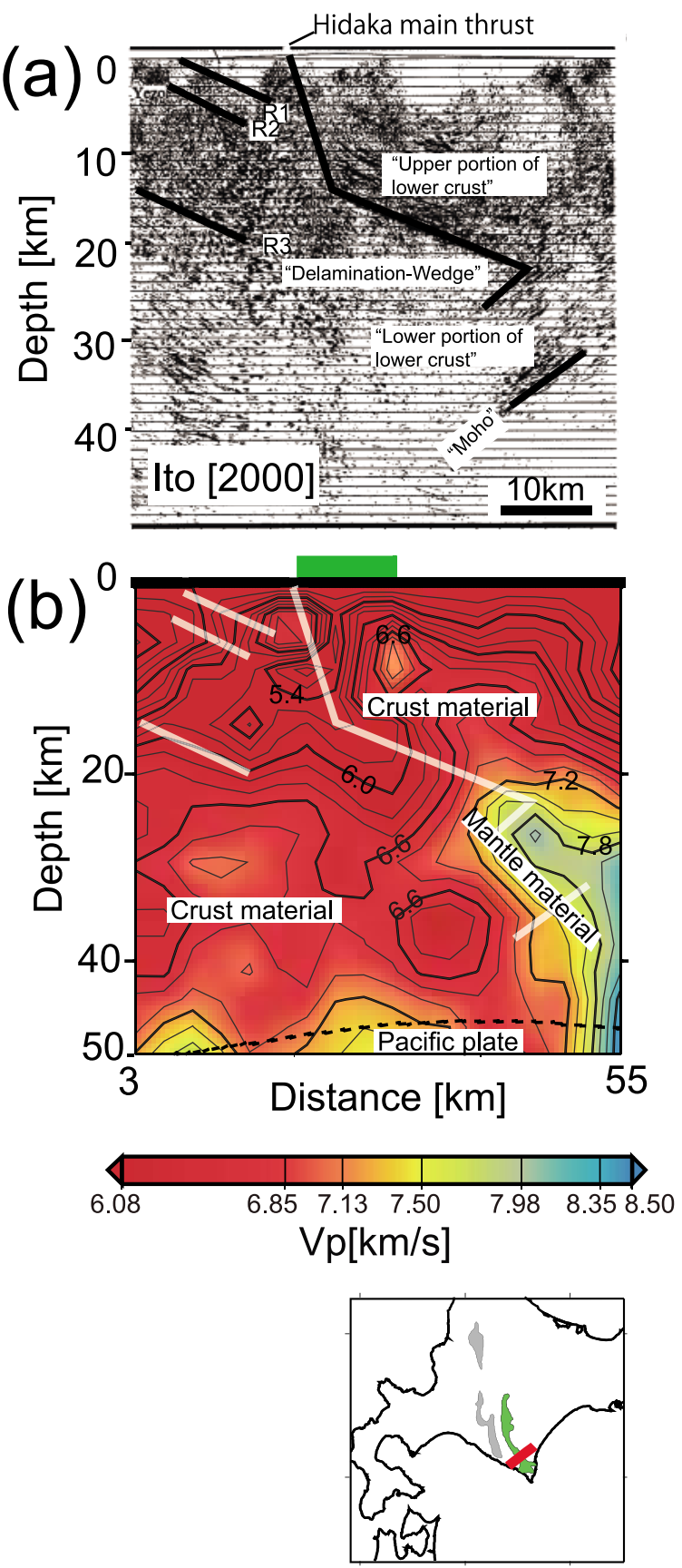

Figure 13. (a) Seismic section obtained by seismic reflection surveys [Ito, 2000] and (b) the seismic velocity structure obtained in this study (enlarged views of Figure 4d) along a line shown by a red line in the inset. 


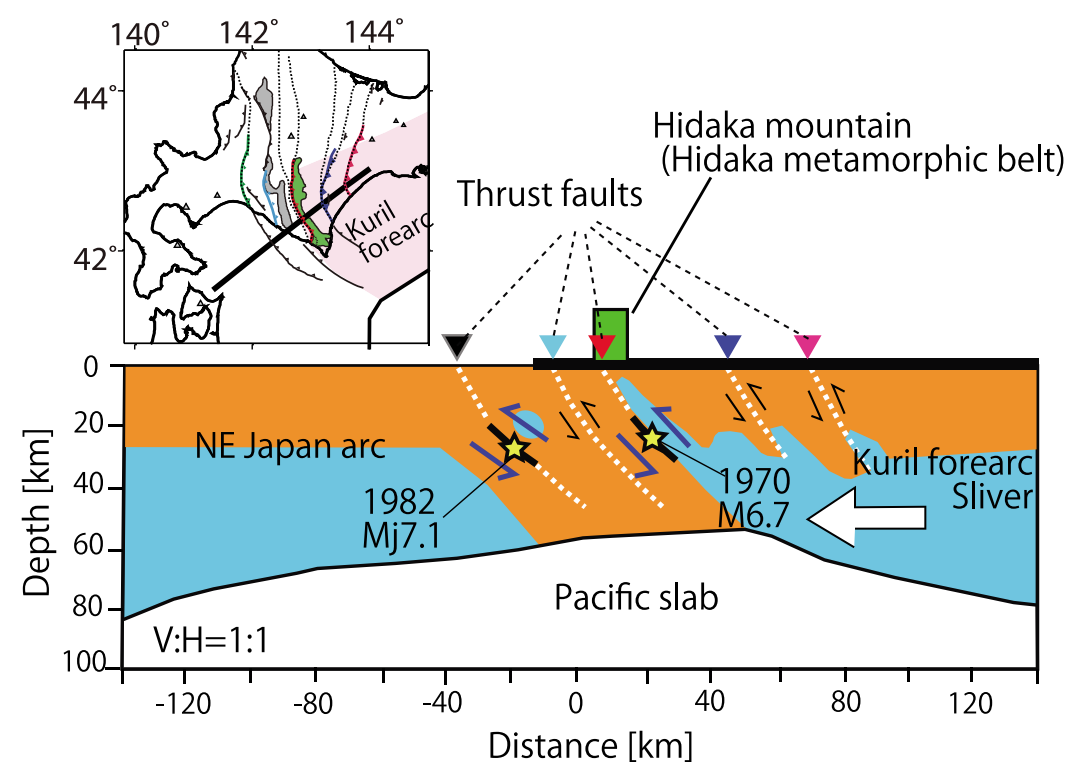

Figure 14. Schematic illustration of the collision between the Kuril and NE Japan forearcs beneath the Hidaka collision zone.

the slab crust was caused by the presence of anomalously deep crustal material that prevents the mantle wedge flow into the normal mantle wedge. Therefore, the locally lower temperatures result in more micro-earthquakes at greater depths. The two large earthquakes (in 1970 and 1982) generated at anomalous large depths are also thought to have resulted from the locally lower temperatures beneath the Hokkaido collision zone.

\subsection{Comparison With the Results of Previous Seismic Reflection Surveys}

[26] Ito [2000, Figure 2] compiled the results of seismic reflection surveys [Japan National Oil Corporation, 1973, 1987, 1993, 1996] and reported the dips of thrust faults on the surface to be $40^{\circ}$ to $50^{\circ}$ beneath the collision zone at depths of 0 to $5 \mathrm{~km}$. These dips are comparable with the results of our study for the structures of alternate layers in the crust material at depths of 5 to $20 \mathrm{~km}$ and high-velocity anomalies at depths of 5 to $35 \mathrm{~km}$, which strike N-S and dip $40^{\circ}$ to $50^{\circ}$.

[27] Tsumura et al. [1999] carried out seismic reflection surveys and compiled the results of theirs and previous surveys [Ikawa et al., 1997; Arita et al., 1998] of the region beneath the Hidaka collision zone. They proposed that the lower crust of the Kuril forearc is delaminated into upper and lower parts due to the collision of the two forearcs, and that the lower part of the Kuril lower crust descends into the mantle wedge. Ito [2000] also compiled profiles of previous studies [Ikawa et al., 1997; Arita et al., 1998; Tsumura et al., 1999]. Figure 13a shows a vertical cross section based on Ito [2000, Figure 3]. Based on these profiles, Ito [2000] also speculated that the lower crust of the Kuril forearc would be delaminated into two parts at a depth of approximately $23 \mathrm{~km}$ due to the collision, forming a "crustal structure like a series of shark's jaws" [Ito, 2000] in the lower crust. The upper part of this crustal feature, which is composed of the upper crust and the upper portion of the lower crust, is thrust westward onto the NE Japan arc, whereas the lower part (i.e., the delaminated lower portion of the lower crust) descends into the mantle wedge (Figure 13a).

[28] Figure 13b shows an enlarged cross section of Figure 3f, which corresponds to the same cross section as in Ito [2000] (Figure 13a). This figure shows that high-velocity mantle material appears beneath the eastern portion of the Hidaka metamorphic belt at depths of 20 to $50 \mathrm{~km}$. The location of this high-velocity material corresponds to the region in which the lower "jaw" of the "lower crustal material" described by Ito [2000] is located. Given that several synthetic tests (CRT, RT, and RRT) have shown that the images obtained of the high-velocity zone are reliable, our results imply that the Kuril arc lower crust might be delaminated, but do not suggest the existence of a crustal structure similar to that described by Ito [2000]. Thus, our study does not indicate that the delaminated lower crustal material of the Kuril forearc continuously descends into the mantle wedge, which is contrary to the results reported in previous studies. In summary, comparison of our velocity structure with that reported by Ito [2000] indicates that the tomographic results obtained in our study agree with the structure obtained by seismic reflection studies at shallow depths $(<20 \mathrm{~km})$, whereas the results at depths of 20 to $50 \mathrm{~km}$ are not in agreement.

\subsection{A New Model of Arc-Arc Collision Beneath the Hokkaido Corner}

[29] The precise seismic tomographic images of our study show that a large low-velocity zone and a small highvelocity zone lie beneath the Hidaka collision zone. The results of the synthetic tests support the existence of anomalous low-velocity and high-velocity zones. As mentioned above, the low-velocity and high-velocity zones would correspond to anomalous crustal and mantle materials, respectively. Taking into account these low- and high-velocity zones, we consider a new model beneath the central Hokkaido region, which is shown schematically in Figure 14. 

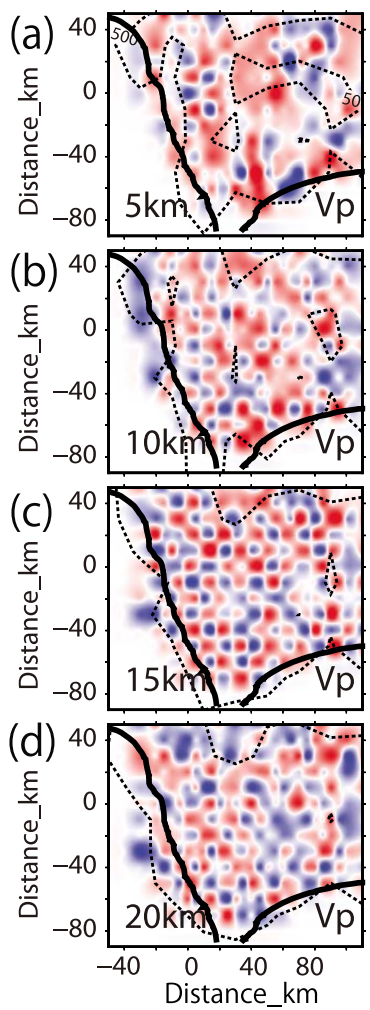
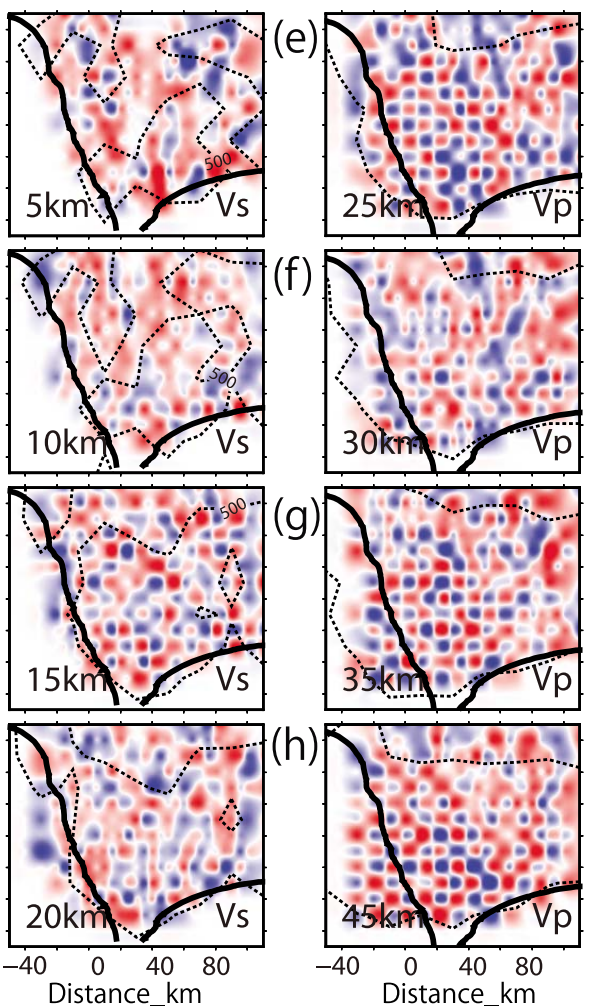

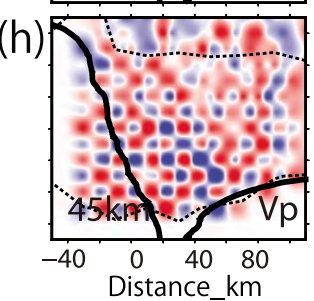

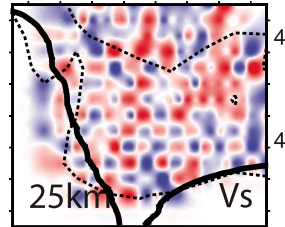
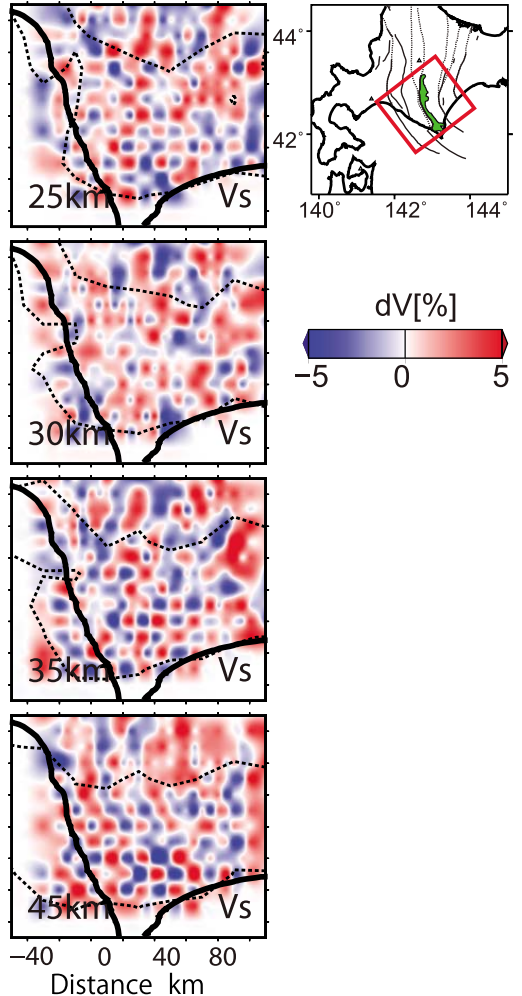

Figure A1. Results of checkerboard resolution tests (horizontal cross-sectional views) with anomaly size of $10 \mathrm{~km}$ [along arc] $\times 10 \mathrm{~km}$ [across arc] $\times 10 \mathrm{~km}$ [depth direction] for (left) P wave and (right) S wave at depths of (a) $5 \mathrm{~km}$, (b) $10 \mathrm{~km}$, (c) $15 \mathrm{~km}$, (d) $20 \mathrm{~km}$, (e) $25 \mathrm{~km}$, (f) $30 \mathrm{~km}$, (g) $40 \mathrm{~km}$, and (h) $45 \mathrm{~km}$ for area shown in the inset map at the top right. The symbols are the same as Figures $3 \mathrm{f}-3 \mathrm{n}$.

[30] In this model, as a result of the southwestward movement of the Kuril forearc, the NE Japan forearc and the Kuril forearc sliver collide beneath central Hokkaido near the Hidaka metamorphic belt, generating a SW-NE compressional stress field. This compressional stress causes deformation of the NE Japan forearc and the Kuril forearc sliver beneath the collision zone along the existing weak zones (thrust faults and geological boundaries). The two large inland earthquakes occurred at the boundaries between two different materials (i.e., in zones with low strength). The $1970 \mathrm{Mj}$ 6.7 Hidaka earthquake occurred on the Hidaka main thrust and the 1982 Urakawa-oki earthquake occurred on the Neogene thrust of the Ishikari Lowland eastern edge fault system.

[31] The anomalous mantle material beneath and to the east of the Hidaka metamorphic belt may be Kuril forearc mantle, which extends from the uppermost mantle of the Kuril forearc. The Horoman peridotite may also originate from this anomalous mantle material beneath the Hidaka metamorphic belt. This hypothesis for the origin of the peridotite is consistent with the geological and petrological study of Sawaguchi [2004], in which the origin of the peridotite is expected to be the uppermost mantle. The geophysical observational results of our present study complement geological and petrological studies on the origin of the Horoman perdotite, on the tectonic evolution of the Hokkaido corner, and on the orogeny, because seismic velocities structures provide a picture of underground structure and the spatial distribution of materials at deep depths, the nature of which has hitherto been speculative.

[32] Although previous studies (e.g., seismic velocities tomographic studies [Kita et al., 2010a]; seismic reflection studies [Ito 2000]; seismic refraction study [Iwasaki et al., 2004]) have indicated that the subducting crustal material appears to extend from the Kuril forearc, our present study indicated that the subducting crustal material appears to extend from the NE Japan forearc because our present study shows that the clearest high-V zone is located beneath the Hidaka metamorphic belt between the two forearcs at shallow depth. However, the possibility that these crustal materials comprise Kuril forearc cannot be dismissed, because the Kuril forearc crust is relatively thin beneath the Hidaka metamorphic belt and to the east of it. Crust that is partially delaminated from the Kuril forearc crust might be part of the low-velocity zone of crustal materials detected in the mantle wedge just above the slab.

\section{Conclusions}

[33] Using a combined data set from a dense nationwide seismic network and a temporary seismic network, we have obtained a high-resolution three-dimensional seismic velocity structure beneath the Hokkaido corner at depths of 0 to $60 \mathrm{~km}$. A broad low-velocity zone $(80 \mathrm{~km} \times 100 \mathrm{~km} \times$ $50 \mathrm{~km}$ ) of $\mathrm{P}$ and $\mathrm{S}$ waves having $\mathrm{P}$ wave velocities of 6.6 to 

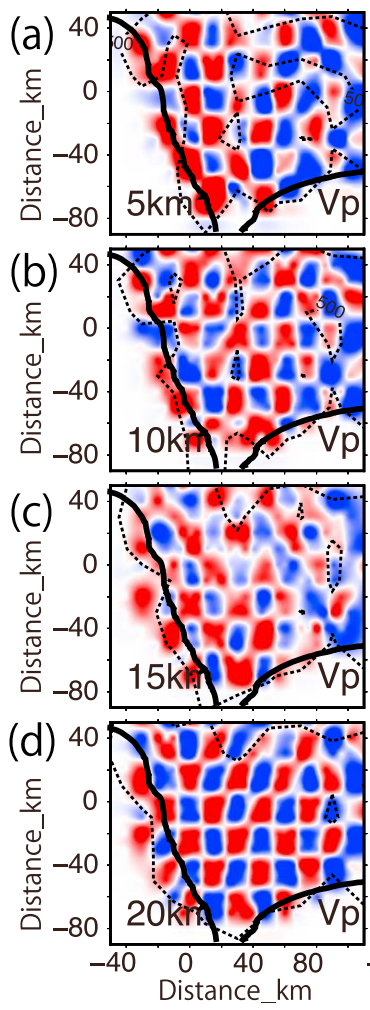
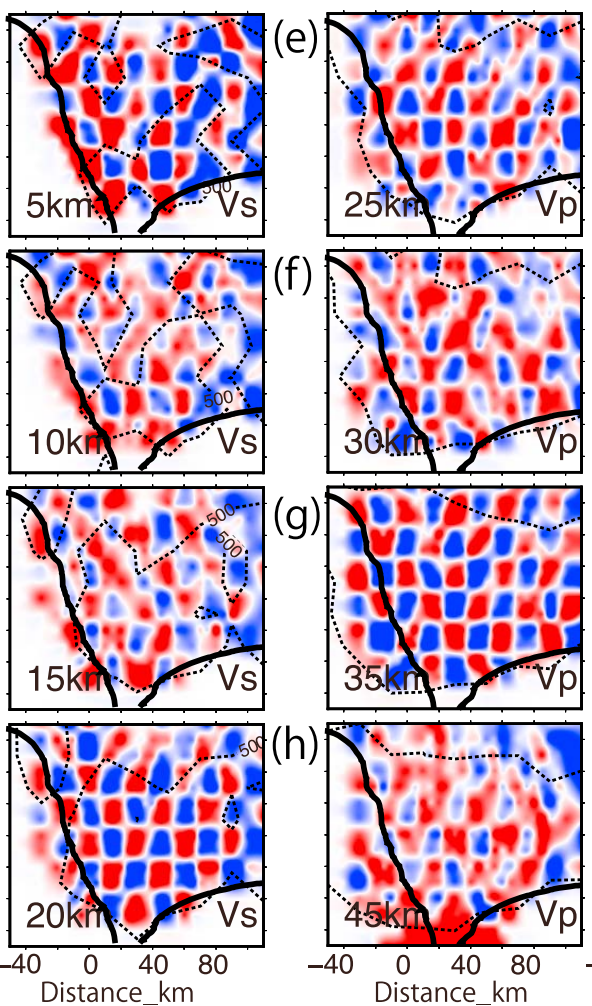

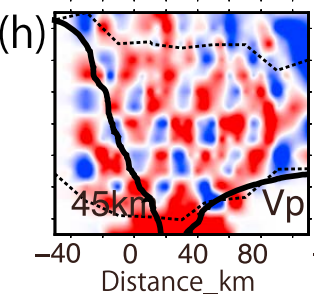

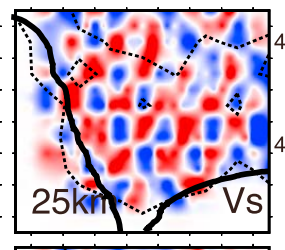
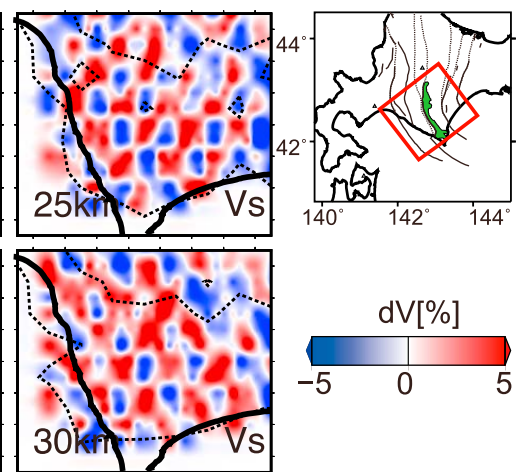

Figure A2. Results of checkerboard resolution tests (horizontal cross-sectional views) with anomaly size of $15 \mathrm{~km}$ [along arc] $\times 20 \mathrm{~km}$ [across arc] $\times 15 \mathrm{~km}$ [depth direction] for (left) $\mathrm{P}$ wave and (right) $\mathrm{S}$ wave at depths of (a) $5 \mathrm{~km}$, (b) $10 \mathrm{~km}$, (c) $15 \mathrm{~km}$, (d) $20 \mathrm{~km}$, (e) $25 \mathrm{~km}$, (f) $30 \mathrm{~km}$, (g) $35 \mathrm{~km}$, and (h) $45 \mathrm{~km}$ shown in the inset map for the area at the top right. The symbols are the same as Figures $3 \mathrm{f}-3 \mathrm{n}$.

$7.2 \mathrm{~km} / \mathrm{s}$ and $\mathrm{S}$ wave velocities of $<4.2 \mathrm{~km} / \mathrm{s}$ is located to the west of the Hidaka metamorphic belt (the Hidaka main thrust) at depths of 35 to $90 \mathrm{~km}$. The velocity values of the low-velocity zone correspond to that of crustal material.

[34] Several small-scale $\mathrm{P}$ and $\mathrm{S}$ wave high-velocity zones were detected at depths of 0 to $35 \mathrm{~km}$, inclined to the eastnortheast at $40^{\circ}$ to $60^{\circ}$. All of these anomalous high-velocity zones are located at the deeper extensions of Neogene thrust faults, striking approximately N-S and dipping $40^{\circ}$ to $50^{\circ}$ at depths of 0 to $10 \mathrm{~km}$. The velocity values of these highvelocity zones (P wave velocities of 7.8 to $8.4 \mathrm{~km} / \mathrm{s}$ and $\mathrm{S}$ wave velocities of 4.5 to $4.8 \mathrm{~km} / \mathrm{s}$ ) at depths of 15 to $35 \mathrm{~km}$ correspond to those of uppermost mantle materials. The clearest high-velocity zone is located just beneath the Hidaka metamorphic belt and is in contact with the eastern edge of the broad low-velocity zone, which is a deep extension of the Hidaka main thrust. This high-velocity zone approaches the surface at the Hidaka metamorphic belt, and the southern edge of this zone is located just beneath surface exposures of the Horoman peridotite.

[35] The boundary between the clearest high-velocity zone and a low-velocity zone corresponds to the fault plane of the $1970 \mathrm{Mj}$ 6.7 Hidaka earthquake. Another small-scale highvelocity zone is located within the broad low-velocity zone at depths of 20 to $30 \mathrm{~km}$ and on the deep extension of one of the thrust faults of the Ishikari Lowland eastern edge fault system. The fault plane of the $1982 \mathrm{Mj} 7.1$ Urakawa-oki earthquake also corresponds to the boundary between this small high-velocity zone and the low-velocity zone. The hanging walls of both of the fault planes of these two large earthquakes have anomalously high velocities, whereas both footwalls have low velocities. The detailed seismic velocity structure presented in our study suggests that the arc-arc collision of the NE Japan and Kuril forearcs is ongoing upon existing thrust faults, producing M7 class earthquakes at anomalously deep depths at sharp material boundaries between uppermost mantle and crustal materials.

\section{Appendix A: Horizontal Cross Sections of the Checkerboard Tests at Depths of 5-45 km}

[36] As mentioned in section 3.2, we performed three kinds of checkerboard tests with perturbation of 5\%. Horizontal cross sections of the checkerboard test with the anomaly size of $10 \mathrm{~km}$ [along arc] $\times 10 \mathrm{~km}$ [across arc] $\times$ 10 [depth direction] $\mathrm{km}$ at depths of 5-45 km are shown in Figure A1. Horizontal cross sections of the results of the checkerboard tests with the anomaly size of $15 \mathrm{~km}$ [along arc] $\times 20 \mathrm{~km}$ [across arc] $\times 15 \mathrm{~km}$ [depth direction] and with that of $20 \mathrm{~km} \times 20 \mathrm{~km} \times 20 \mathrm{~km}$ are shown in Figure A2 and Figure A3, respectively. Vertical slices of the results are shown in Figure A4 $(15 \mathrm{~km} \times 20 \mathrm{~km} \times 15 \mathrm{~km})$ and Figure A5 $(20 \mathrm{~km} \times 20 \mathrm{~km} \times 20 \mathrm{~km})$, respectively. 

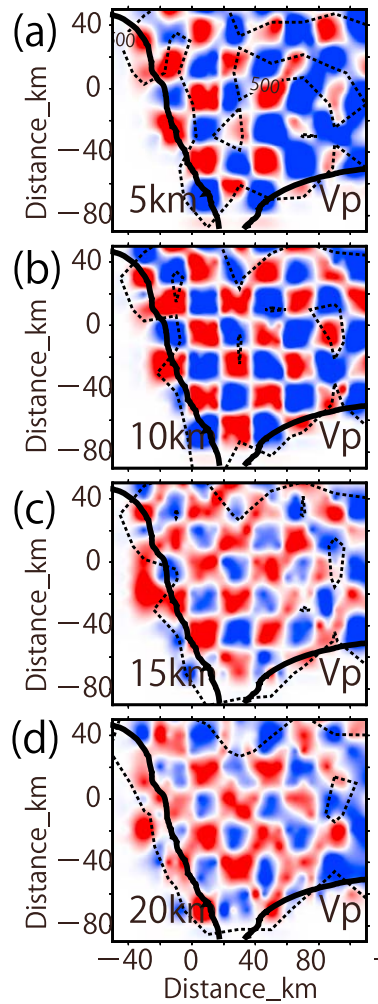
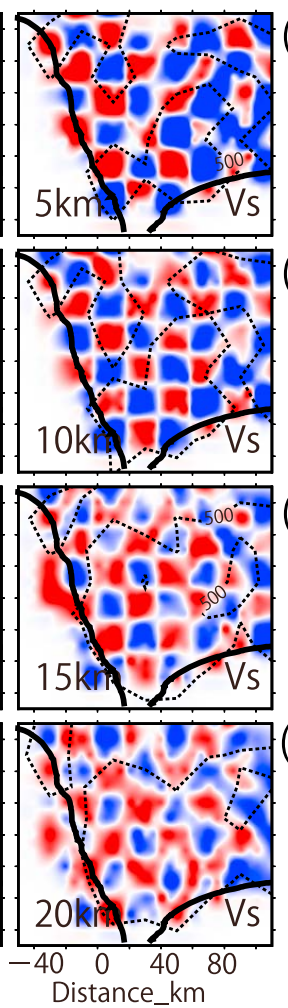
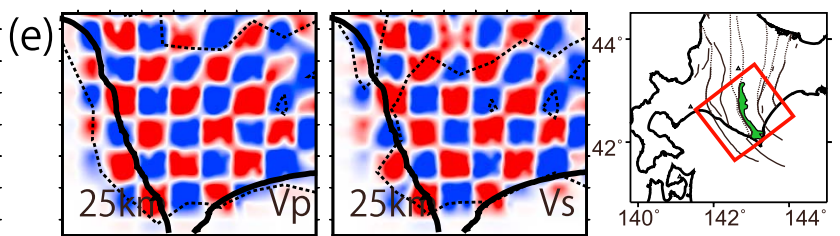

(f)
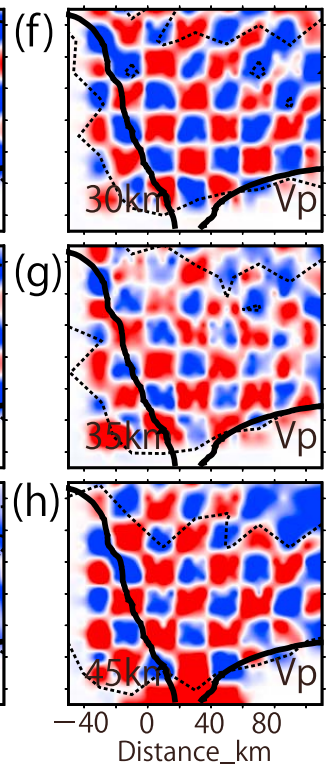
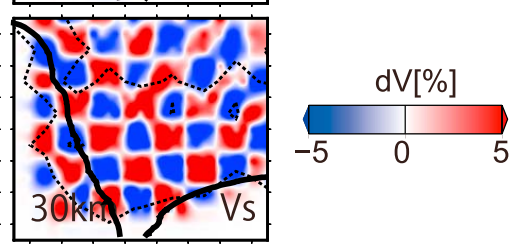

Figure A3. Results of checkerboard resolution tests (horizontal cross-sectional views) with anomaly size of $20 \mathrm{~km}$ [along arc] $\times 20 \mathrm{~km}$ [across arc] $\times 20 \mathrm{~km}$ [depth direction] for (left) P wave and (right) S wave at depths of (a) $5 \mathrm{~km}$, (b) $10 \mathrm{~km}$, (c) $15 \mathrm{~km}$, (d) $20 \mathrm{~km}$, (e) $25 \mathrm{~km}$, (f) $30 \mathrm{~km}$, (g) $35 \mathrm{~km}$, and (h) $45 \mathrm{~km}$ shown in the inset map for the area at the top right. The symbols are the same as Figures $3 \mathrm{f}-3 \mathrm{n}$. 


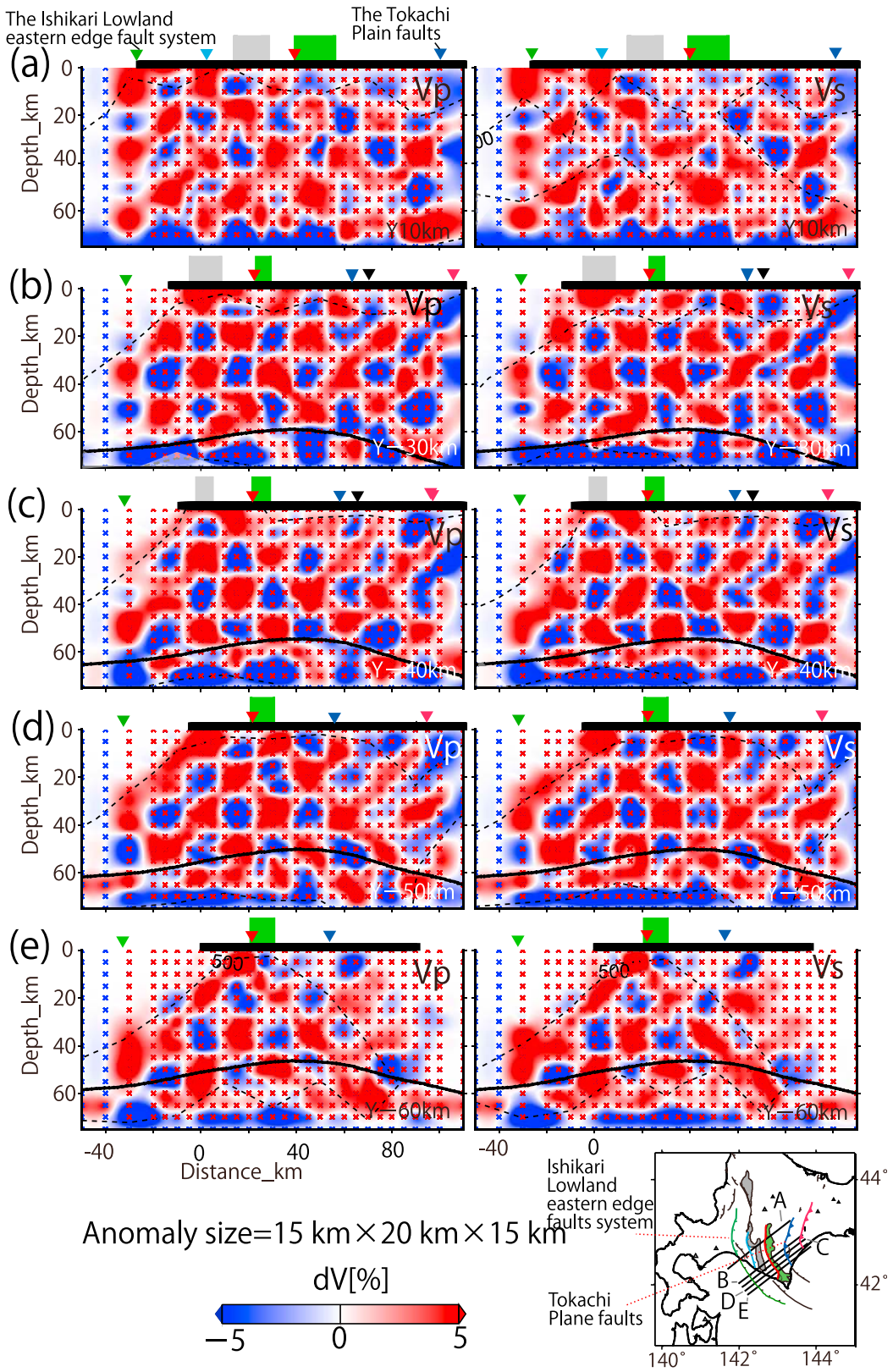

Figure A4. Results of checkerboard resolution tests (vertical cross-sectional views of along-arc) with anomaly size of $15 \mathrm{~km}$ [along arc] $\times 20 \mathrm{~km}$ [across arc] $\times 15 \mathrm{~km}$ [depth direction] for (left) $\mathrm{P}$ wave and (right) $\mathrm{S}$ wave along lines (a) A, (b) B, (c) C, (d) D, and (e) E shown in the inset map at the bottom. The other symbols are the same as in Figures $4 \mathrm{a}-4 \mathrm{e}$. 


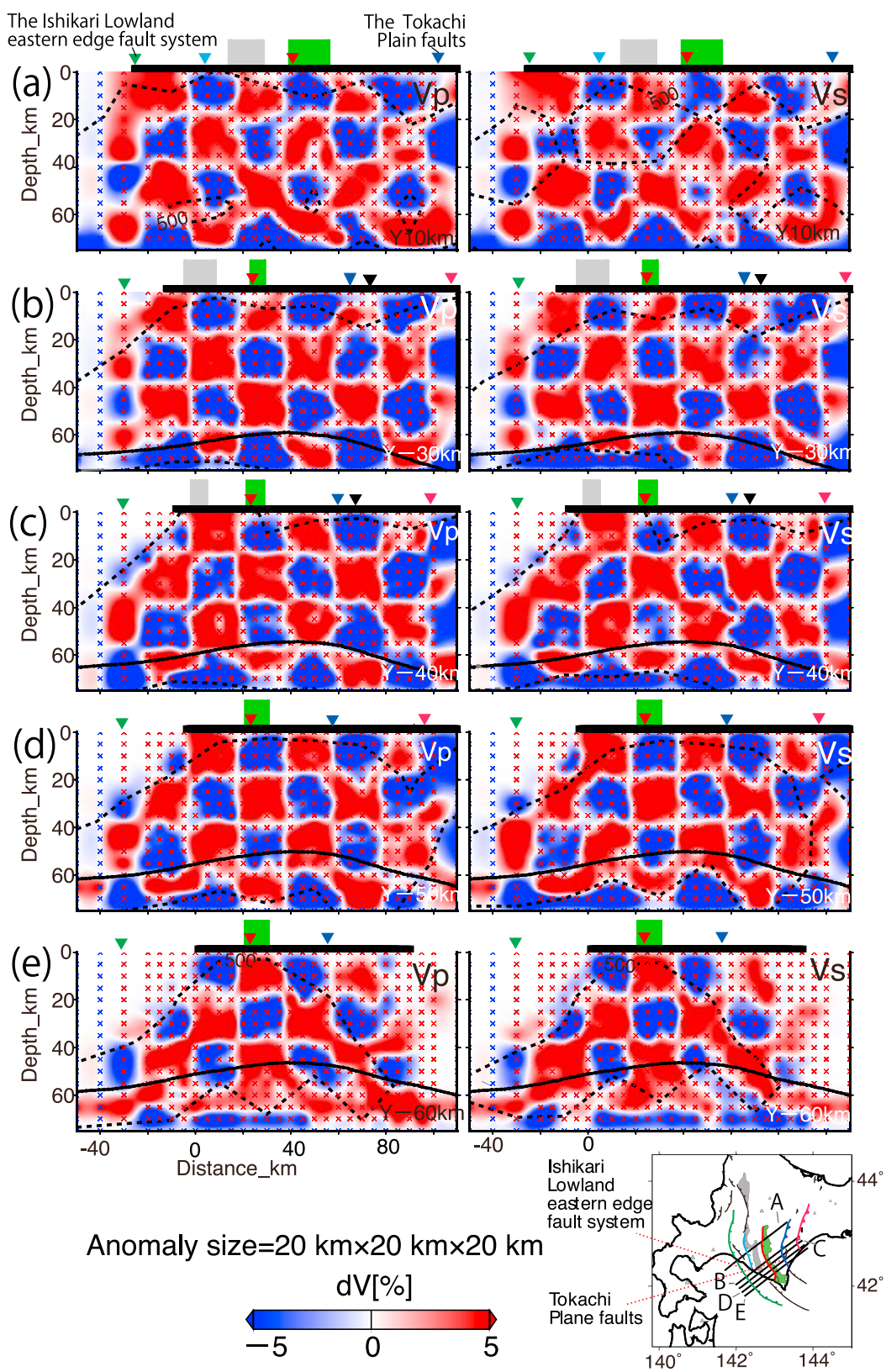

Figure A5. (a-e) Results of checkerboard resolution tests (vertical cross-sectional views of along-arc) with anomaly size of $20 \mathrm{~km}$ [along arc] $\times 20 \mathrm{~km}$ [across arc] $\times 20 \mathrm{~km}$ [depth direction]. The other symbols are the same as in Figure A4.

[37] Acknowledgments. The data analyzed in this study were obtained from temporary seismic networks and from the seismic networks of the JMA, NIED (Hi-net), Hokkaido University, Hirosaki University, and Tohoku University. Special thanks are due to seismologists from 11 universities (Hokkaido University, Tohoku University, Yamagata University, University of Tokyo, Nagoya, Gifu University, Kanazawa University, Kyoto University, Tottori University, Kyusyu University, and Kagoshima University) for data obtained with a dense temporary seismic network from 1999 to 2001, in and around the Hokkaido collision zone. We would also like to thank Eiichi Takazawa, Natsue Abe, and Takehiko Hiraga for providing details on the Horoman peridotite. Masaki Takahashi, Kazuhito Ozawa, Takashi Sawaguchi, Toshiaki Shimura, Sumio Miyashita, Tsuyoshi Toyoshima, Gaku Kimura, Jun Moto, Koichi Nakamura, Reishi Takashima, and Takeyoshi Yoshida are thanked for their discussions on geological and petrological aspects of the Hidaka collision. Satoko Murotani and Kazuko Noguchi kindly provided seismographs of the 1970 Hidaka earthquake. Ryosuke Azuma and Mako Ohzono kindly provided the original paper of Moriya et al. [1983] for study of the 1982 Urakawa-oki earthquake. GMT by P. Wessel and W. H. F. Smith was used to prepare the figures. Support to author K.S. through the Global COE Program (Earth Planetary Dynamics) of Tohoku University is greatly appreciated. Thoughtful comments by Robert Nowack, an Associate Editor, and two anonymous reviewers significantly improved the manuscript. This study was also supported by the Japan Society for the Promotion of Science through a Grant-in-Aid for Scientific Research (B) 23740329

\section{References}

Arita, K., et al. (1998), Crustal structure and tectonics of the Hidaka Collision Zone, Hokkaido (Japan), revealed by vibroseis seismic reflection and gravity surveys, Tectonophysics, 290, 197-210.

Christensen, N. I. (1996), Poisson's ratio and crustal seismology, J. Geophys. Res., 101(B2), 3139-3156, doi:10.1029/95JB03446. 
Fuji, S., and T. Moriya (1983), Upper crustal structure in the Hidaka district by refraction measurements using the quarry blasts [in Japanese with English abstract and figure captions], Geophys. Bull. Hokkaido Univ., 42, 169-190.

Geographical Survey Institute (1998), Results of the continuous GPS observations all over Japan [in Japanese with English figure captions], in Report of the Coordinating Committee for Earthquake Prediction, vol. 59, 614-633, Coord. Comm. for Earthquake Predict., Tsukuba, Japan.

Geological Survey of Japan (1992), Geological Atlas of Japan, 2nd ed., Asakura, Tokyo.

Gephart, J. W., and D. W. Forsyth (1984), An improved method for determining the regional stress tensor using earthquake focal mechanisms data: application to the San Fernando earthquake sequence, J. Geophys. Res., 89, 9305-9320 doi:10.1029/JB089iB11p09305.

Hasegawa, A., N. Umino, and A. Takagi (1978), Double-planed structure of the deep seismic zones in the northeastern Japan arc, Tectonophysics, 47, 43-58, doi:10.1016/0040-1951(78)90150-6

Horiuchi, S., K. Emura, and T. Hirasawa (1972), Reliability of pressure and tension axes determined by initial motions of P-waves from deep earthquakes in and near Japan: The use of J. M. A. network, J. Seismol. Soc. Jpn., 25(1), 92-104.

Ichikawa, M. (1971), Reanalysis of the mechanisms of earthquakes which occurred in and near Japan and statistical studies on the nodal plane solutions obtained, 1926-1968, Geophys. Mag., 35, 207-273.

Ikawa, T., et al. (1997), The vibroseismic reflection profile of the ldon'nappu belt of the front of the Hidaka collision zone [in Japanese], paper presented at 104th Annual Meeting of the Geological Society of Japan, Geol. Soc. of Japan, Fukuoka, Japan.

Ito, T. (2000), Crustal structure of the Hidaka collision zone and its foreland fold-and-thrust belt, Hokkaido, Japan [in Japanese with English abstract], J. Jpn. Assoc. Pet. Technol., 65, 103-109, doi:10.3720/japt.65.103.

Ito, T., et al. (1999), Delamination wedge structure beneath the Hidaka collision zone [in Japanese], Chikyu Mon., 21(3), 130-136.

Ito, Y., Y. Asano, and K. Obara (2009), Very-low-frequency earthquakes indicate a transpressional stress regime in the Nankai accretionary prism, Geophys. Res. Lett., 36, L20309, doi:10.1029/2009GL039332.

Iwasaki, T., O. Ozel, T. Moriya, S. Sakai, S. Suzuki, G. Aoki, T. Maeda, and T. Iidaka (1998), Lateral structural variation across a collision zone in central Hokkaido, Japan, as revealed by wide-angle seismic experiments, Geophys. J. Int., 132, 435-457, doi:10.1046/j.1365-246x.1998.00454.x.

Iwasaki, T., K. Adachi, T. Moriya, H. Miyamachi, T. Matsushima, K. Miyashita, T. Takeda, T. Taira, T. Yamada, and K. Ohtake (2004), Upper and middle crustal deformation of an arc-arc collision across Hokkaido, Japan, inferred from seismic refraction/wide-angle reflection experiments, Tectonophysics, 388, 59-73, doi:10.1016/j.tecto.2004.03.025.

Japan National Oil Corporation (1973), Research report for area from Hidaka to Oshima by Basic geophysical explosion, report, Tokyo.

Japan National Oil Corporation (1987), Research report for area from the southern Hokkaido (Donan) to Shimokita-oki by basic geophysical explosion, report, Tokyo.

Japan National Oil Corporation (1993), Research report of the Hidaka region by basic land geophysical explosion, report, Tokyo.

Japan National Oil Corporation (1996), Research report of the shallow sea area of the Iburi-oki by basic marine geophysical explosion, report, Tokyo.

Kanamori, H., and H. Mizutani (1965), Ultrasonic measurement of elastic constants of rocks under high pressures, Bull. Earthquake Res. Inst. Univ Tokyo, 43, 173-194.

Katsumata, K., et al. (2002), Distribution of hypocenters and focal mechanisms in and around the Hidaka arc-arc collision zone revealed by a dense temporary seismic network [in Japanese], Bull. Earthquake Res. Inst. Univ. Tokyo, 77, 199-223.

Katsumata, K., N. Wada, and M. Kasahara (2003), Newly imaged shape of the deep seismic zone within the subducting Pacific plate beneath the Hokkaido corner, Japan-Kurile arc-arc junction, J. Geophys. Res., 108(B12), 2565, doi:10.1029/2002JB002175.

Katsumata, K., N. Wada, and M. Kasahara (2006), Three-dimensional $\mathrm{P}$ and $\mathrm{S}$ wave velocity structures beneath the Hokkaido corner, JapanKurile arc-arc junction, Earth Planets Space, 58, e37-e40.

Kimura, G. (1994), The latest Cretaceous-early Paleogene rapid growth of accretionary complex and exhumation of high pressure series metamorphic rocks in northwestern Pacific margin, J. Geophys. Res., 99 , 22,147-22,164, doi:10.1029/94JB00959.

Kimura, G. (1996), Collision orogeny at arc-arc junctions in the Japanese Islands, Isl. Arc, 5, 262-275, doi:10.1111/j.1440-1738.1996.tb00031.x.

Kita, S., T. Okada, J. Nakajima, T. Matsuzawa, and A. Hasegawa (2006), Existence of a seismic belt in the upper plane of the double seismic zone extending in the along-arc direction at depths of 70-100 km beneath NE Japan, Geophys. Res. Lett., 33, L24310, doi:10.1029/2006GL028239.
Kita, S., T. Okada, A. Hasegawa, J. Nakajima, and T. Matsuzawa (2010a), Anomalous deepening of a seismic belt in the upper-plane of the double seismic zone in the Pacific slab beneath the Hokkaido corner: Possible evidence for thermal shielding caused by subducted forearc crust materials, Earth Planet. Sci. Lett., 290, 415-426, doi:10.1016/j.epsl.2009.12.038.

Kita, S., T. Okada, A. Hasegawa, J. Nakajima, and T. Matsuzawa (2010b), Existence of interplane earthquakes and neutral stress boundary between the upper and lower planes of the double seismic zone beneath Tohoku and Hokkaido, northeastern Japan, Tectonophysics, 496, 68-82, doi:10.1016/ j.tecto.2010.10.010.

Komatsu, M., and M. Nochi (1966), Ultrabasic rocks in the Hidaka metamorphic belt, Hokkaido, Japan. I. Mode of occurrence of the Horoman ultrabasic rocks, Chikyu Kagaku, 87, 21-29.

Komatsu, M., S. Miyashita, J. Maeda, Y. Osanai, and T. Toyoshima (1983), Disclosing of a deepest section of continental-type crust upthrust as the final event of collision of arcs in Hokkaido, North Japan, in Accretion Tectonics in the Circum-Pacific Regions, edited by M. Hashimoto and S. Uyeda, pp. 149-165, Terrapub, Tokyo.

Kosuga, M., T. Sato, A. Hasegawa, T. Matsuzawa, S. Suzuki, and Y. Motoya (1996), Spatial distribution of intermediate-depth earthquakes with horizontal or vertical nodal planes beneath northeastern Japan, Phys. Earth Planet. Inter., 93, 63-89, doi:10.1016/0031-9201(95)03089-1.

Miyamachi, H., and T. Moriya (1984), Velocity structure beneath the Hidaka Mountains in Hokkaido, Japan, J. Phys. Earth, 32, 13-42, doi:10.4294/jpe1952.32.13

Miyamachi, H., M. Kasahara, S. Suzuki, K. Tanaka, and A. Hasegawa (1994), Seismic velocity structure in the crust and upper mantle beneath northern Japan, J. Phys. Earth, 42, 269-301, doi:10.4294/jpe1952.42.269.

Moriya, T. (1972), Aftershock activity of the Hidaka Mountains earthquake of January 21, 1970 [in Japanese with English figure captions], J. Seismol. Soc. Jpn., 24, 287-297.

Moriya, T., H. Miyamachi, and S. Katoh (1983), Spatial distribution and mechanism solutions for foreshocks, mainshock an aftershocks of the Urakawa-oki Earthquake of March 21, 1982 [in Japanese with English figure captions], Geophys. Bull. Hokkaido Univ., 42, 191-213.

Moriya, T., H. Okada, T. Matsushima, S. Asano, T. Yoshii, and A. Ikami (1998), Collision structure in the upper crust beneath the southwestern foot of the Hidaka Mountains, Hokkaido, Japan as derived from explosion seismic observations, Tectonophysics, 290, 181-196, doi:10.1016/ S0040-1951(98)00011-0

Murai, Y., et al. (2003), Delamination structure imaged in the source area of the 1982 Urakawa-oki earthquake, Geophys. Res. Lett., 30(9), 1490, doi:10.1029/2002GL016459.

Niida, K. (1984), Petrology of the Horoman ultramafic rocks in the Hidaka metamorphic belt, Hokkaido, Japan, J. Fac. Sci., Hokkaido Univ., Ser. 4 $21,197-250$

Ogiso, M., K. Yomogida, and K. Katsumata (2005), Recursive travel-time inversion: A tool for real-time seismic tomography, Earth Planets Space, $57,477-489$.

Omuralieva, A. M., A. Hasegawa, T. Matsuzawa, J. Nakajima, and T. Okada (2012), Lateral variation of the cutoff depth of shallow earthquakes beneath the Japanese Islands and its implications for seismogenesis, Tectonophysics, 518-521, 93-105, doi:10.1016/j.tecto.2011.11.013. Ozawa, K. (2004), Thermal history of the Horoman Peridotite Complex: A record of thermal perturbation in the lithospheric mantle, J. Petrol., 45(2), 253-273, doi:10.1093/petrology/egg110.

Sawaguchi, T. (2004), Deformation history and exhumation process of the Horoman Peridotite Complex, Hokkaido, Japan, Tectonophysics, 379 , 109-126, doi:10.1016/j.tecto.2003.10.011.

Shimura, T., M. Owada, Y. Osanai, M. Komatsu, and H. Kagami (2004), Variety and genesis of the pyroxene-bearing S- and I-type granitoids from the Hidaka Metamorphic Belt, Hokkaido, northern Japan, Trans. R. Soc Edinburgh Earth Sci., 95, 161-179, doi:10.1017/S0263593300000997.

Takanami, T. (1982), Three-dimensional seismic structure of the crust and upper mantle beneath the orogenic belts in southern Hokkaido, Japan, J. Phys. Earth, 30, 87-104, doi:10.4294/jpe1952.30.87.

Takazawa, E., F. A. Frey, N. Shimizu, A. Saal and M. Obata (1999), Polybaric petrogenesis of mafic layers in the Horoman Peridotite Complex, Japan, J. Petrol., 40(12), 1827-1851.

Tanaka, A. (2004), Geothermal gradient and heat flow data in and around Japan (II): Crustal thermal structure and its relationship to seismogenic layer, Earth Planets Space, 56, 1195-1199.

Thurber, C. H., and D. Eberhart-Phillips (1999), Local earthquake tomography with flexible gridding, Comput. Geosci., 25, 809-818, doi:10.1016/ S0098-3004(99)00007-2.

Tsumura, N., H. Ikawa, T. Ikawa, M. Shinohara, T. Ito, K. Arita, T. Moriya, G. Kimura and T. Ikawa (1999), Delamination-wedge structure beneath the Hidaka Collision Zone, central Hokkaido, Japan inferred from seismic 
reflection profiling, Geophys. Res. Lett., 26(8), 1057-1060, doi:10.1029/ 1999GL900192.

Yamamoto, A. (2002), Gravity anomaly around the Hidaka collision zone [in Japanese], Chikyu Mon., 24(7), 488-494.

Yamamoto, A., M. Saito, K. Yamada, and H. Ishikawa (2001a), Gravity anomaly and crustal structure around the southern part of the Hidaka Collision Zone in Hokkaido, Japan, Geophys. Bull. Hokkaido Univ., 64, 21-49.

Yamamoto, A., K. Yamada, M. Saito, and H. Ishikawa (2001b), Gravity anomaly around the Horoman Peridotite region, central Hokkaido, Japan, Geophys. Bull. Hokkaido Univ., 64, 51-80.
Zhang, H., and C. H. Thurber (2003), Double-difference tomography: The method and its application to the Hayward fault, California, Bull. Seismol. Soc. Am., 93, 1875-1889.

Zhang, H., and C. H. Thurber (2006), Development and applications of double-difference seismic tomography, Pure Appl. Geophys., 163, 373-403, doi:10.1007/s00024-005-0021-y.

Zhao, D., A. Hasegawa, and S. Horiuchi (1992), Tomographic imaging of $\mathrm{P}$ and $\mathrm{S}$ wave velocity structure beneath northeastern Japan, J. Geophys. Res., 97, 19,909-19,928, doi:10.1029/92JB00603. 